\title{
REFLEXIONES PARA UN FUTURO PROGRAMA DE PROTECCIÓN SOCIAL EN VENEZUELA
}

Eugenio Díaz-Bonilla, Patricia Biermayr-Jenzano y Florencia Paz 


\section{CONTENIDOS}

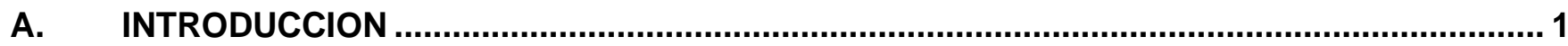

B. ALGUNOS ASPECTOS DE LA SITUACIÓN ACTUAL EN VENEZUELA ................................ 1

C. BREVE REVISION DE PROGRAMAS DE PROTECCIÓN SOCIAL EN ALC ............................5

a) Diferentes tipos de programas de asistencia social y gasto asociado ................................... 5

b) Programas de transferencias condicionadas ................................................................ 11

c) Programas de alimentación escolar............................................................................. 13

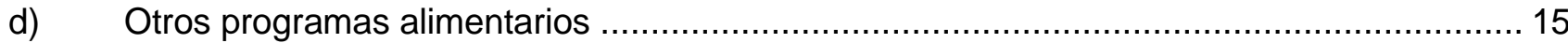

D. ALGUNAS REFLEXIONES SOBRE PROGRAMAS DE PROTECCIÓN SOCIAL Y AYUDA

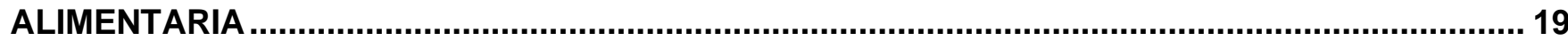

a) Consideraciones generales: estrategia de desarrollo y estabilidad macroeconómica .......... 19

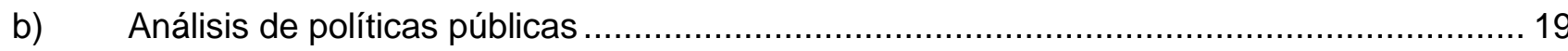

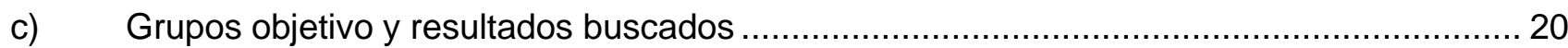

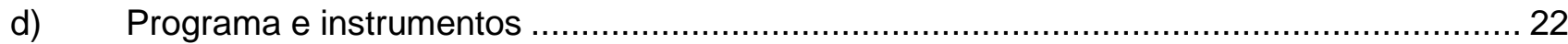

e) Programas especiales de transferencias para pobres rurales ..........................................2 23

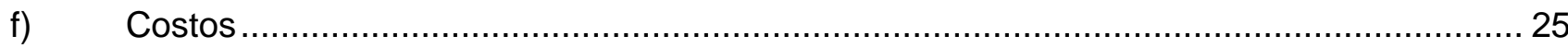

g) Organización y gobernanza de los programas........................................................... 26

h) Estadísticas, sistemas de información, y monitoreo y evaluación ........................................2 27

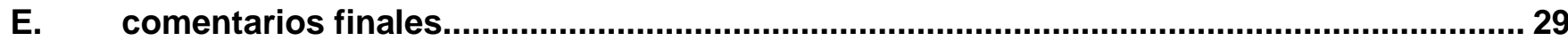

ANEXO 1. PROGRAMAS DE COMPLEMENTACION ALIMENTARIA ESCOLAR EN PAISES

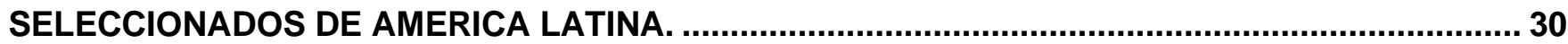

BIBLIOGRAFIA

SOBRE LOS AUTORES

\section{CUADROS}

Cuadro 1: Caracterización de medidas de protección social. ............................................................ 4

Cuadro 2: Clasificación de Programas en la base ASPIRE .......................................................... 5

Cuadro 3: Programas de transferencias condicionadas en América Latina y el Caribe, según país y según si están operando o no, 1996-2015 
Cuadro 4: Estimado de Costos para Diferentes Opciones de Corto Plazo de Ayuda Alimentaria y Redes de Protección Social

\section{GRÁFICOS}

Gráfico 1: Programas de Asistencia Social como \% del PBI.................................................... 8

Gráfico 2: Asistencia Social (\% del PIB) .............................................................................. 9

Gráfico 3: Incidencia en Beneficiarios y de los Beneficios (por quintil) ..................................... 10

Gráfico 4: Gastos en Comedores Escolares (\% PBI) .............................................................. 15

Gráfico 5: Programas Alimentarios (\% PBI) ............................................................................. 16 


\section{A. INTRODUCCION ${ }^{1}$}

Venezuela está sufriendo una crisis política, económica y social sin precedentes. La economía ha estado cayendo por 7 años consecutivos, y con los estimados de $-35 \%$ en 2019 y $-25 \%$ en 2020 sería solamente una cuarta parte del valor de 2013. También la inflación ha llegado a niveles inconcebibles, como más de $65,000 \%$ en 2018 , casi $20,000 \%$ en $2019 y$ un estimado de $6,500 \%$ estimado para 2020. En línea con esta catástrofe general, los datos de la ENCOVI 2020 realizada por la Universidad Católica Andrés Bello (UCAB) de ese país, muestran niveles dramáticos de deterioro social: más del $79 \%$ de los venezolanos está en la indigencia (es decir no tienen los ingresos suficientes para cubrir la canasta de alimentos) y alrededor del $96 \%$ está en condiciones de pobreza. Estos datos cuantitativos, con lo terribles que son, no alcanzan a reflejar la tragedia y el sufrimiento humano que representan.

Dada la incertidumbre tanto respecto de la evolución de la situación política, como del desarrollo de la pandemia relacionada con el COVID-19, este documento solamente presenta algunas ideas para un futuro programa de protección social en Venezuela, basado en experiencias de América Latina y el Caribe (ALC). Esto requiere considerar tanto los programas existentes antes de la pandemia en varios países, como de los ajustes realizados en función de la misma y especular acerca de ese futuro incierto del período posterior a la crisis actual.

Este documento está organizado de la siguiente manera. Primero, se analizan indicadores de la situación actual en Venezuela. Luego se presenta una breve revisión de programas de protección social en ALC. Finalmente, se presentan algunas reflexiones sobre programas de protección social y alimentaria.

\section{B. ALGUNOS ASPECTOS DE LA SITUACIÓN ACTUAL EN VENEZUELA}

El objetivo de este documento no es hacer un diagnóstico de las condiciones actuales en Venezuela. Así, aspectos de la situación previa a la pandemia y del impacto del COVID-19, en función de los detallados estudios de la UCAB en la ENCOVI 2019 y las actualizaciones en relación con la pandemia, sirven para contextualizar el trabajo, pero no constituyen el foco del análisis.

Ya en 2019, según datos de la ENCOVI 2019 de la UCAB, los indicadores socio-económicos en Venezuela muestran un panorama desolador:

\footnotetext{
${ }^{1}$ Se agradecen especialmente los comentarios de David Ortega y Juan Carlos Guevara.
} 
- Venezuela era el país con mayor nivel de pobreza en América Latina y el Caribe (ver las cifras mencionadas al inicio) aún peor que Haití y el segundo más desigual después de Brasil.

- La inseguridad alimentaria total (es decir el agregado de los tres niveles de inseguridad leve, moderada, y severa) había subido del 88\% de la población en 2018 hasta el 93\% en 2019. Especialmente la moderada subió del 31\% al 36\% mientras que la severa pasó del 32\% al 33\%.

- El consumo de calorías en los dos quintiles más bajos estaba por debajo de los 2000 kcal diarios por persona, mientras que todos los quintiles tenían consumos per cápita de proteínas muy por debajo de los requerimientos (51 g/día/persona), y los tres quintiles más bajos estaban por debajo del $30 \%$ de esos requerimientos.

- El estado nutricional de menores de cinco años mostraba un 8\% con desnutrición global (medida en peso por edad) y un $21 \%$ se encontraba en situación de riesgo, mientras que, usando la medida de baja talla por edad, el porcentaje llegaba a un $30 \%$, con un $28 \%$ en riesgo.

- Mientras que en 2018 el 88\% de los hogares formaban parte del programa de distribución de alimentos CLAP y recibieron en alguna oportunidad la caja correspondiente, en 2019 la proporción de hogares beneficiarios subía al 92\%.

- Sin embargo, el 5\% de los pobres extremos no reciben la caja CLAP y el $22 \%$ de los no pobres o no pobres extremos sí la reciben. Además, mientras que un 39\% dice recibir al menos 1 caja al mes; $15 \%$ indican que la reciben cada dos meses, y un $46 \%$ sin periodicidad definida.

- Por ello, el impacto estimado por la ENCOVI es que, en conjunto, los programas han tenido un efecto muy limitado en la reducción de la pobreza.

En base a la información disponible, la UCAB estimaba que un programa de transferencias que permitiera cerrar la brecha de pobreza extrema tendría que transferir algo más del equivalente de 2 dólares al día a unos 6,5 millones de hogares. Bajo el supuesto de una focalización perfecta, esto significa que se requeriría un presupuesto de cerca de 5,000 millones de dólares anuales.

En 2020, con Venezuela sufriendo el impacto de la pandemia, la UCAB realizó la "Encuesta de seguimiento al impacto socioeconómico del COVID19" o ETA 2020. Algunas de los resultados preliminares (ya que la pandemia aún está en evolución) son los siguientes.

- La inseguridad alimentaria total subió del 93\% en 2019 al 97\% durante el período de la encuesta, y especialmente la inseguridad alimentaria moderada que pasó del $36 \%$ al $41 \%$ (la inseguridad alimentaria severa se mantuvo en el $33 \%$ ).

- Un $70 \%$ de los hogares declararon que un impacto principal de la pandemia ha sido el aumento de los precios de los alimentos. 
- Se ha computado una pérdida de empleos de casi el 7\% a nivel nacional, y de más de $10 \%$ en las áreas más afectadas por las restricciones de movilidad (como la zona Capital).

- Hasta un $43 \%$ de los hogares del país han reportado imposibilidad de trabajar o pérdida de ingresos (en lo que también influye la falta de gasolina). Entre los grupos más afectados se encuentran los trabajadores por cuenta propia y empleadores; los sectores de transporte, construcción, restaurantes, hoteles y servicios; y las regiones Llanera, Andina y Central.

- Mientras que un $25 \%$ de los hogares declararon recibir transferencias de instituciones públicas entre octubre 2019 y febrero de 2020, el porcentaje aumentó al 52\% en marzo/abril. Pero han caída otras transferencias como las remesas.

Por su parte, en marzo de 2020, WorldVision ${ }^{2}$ realizó una encuesta en cinco estados (Caracas, Lara, Miranda, Táchira y Zulia, abarcando 12 municipios y 12 comunidades) alcanzando 1.388 encuestas hogares y 35 entrevistas a informantes claves. La misma se enfocó en obtener información sobre los sectores programáticos fundamentales tales como salud, agua, medios de vida, saneamiento y educación. Las principales consecuencias observadas son:

- Más del $40 \%$ de los hogares encuestados tienen más de 5 miembros, y se observa que existió una tendencia a los hogares a aumentar su tamaño, lo que indica que los mismos han cambiado la configuración hacia hogares multifamiliares como estrategias de subsistencia para combinar recursos.

- Un $27 \%$ de los hogares reportan que algún miembro ha migrado, la mayoría a países de la región, específicamente Colombia. En términos absolutos, la Plataforma de Coordinación para Refugiados y Migrantes de Venezuela (R4V) calcula que existen alrededor de 5.4 millones de Venezolanos en el exterior. ${ }^{3}$

- Ocho de cada 10 hogares se consideran pobres, con la indigencia/pobreza extrema alcanzando el $71 \%$ de los encuestados.

- En cuanto a la principal fuente de ingresos el $26 \%$ depende de pensiones, $11 \%$ ayuda humanitaria y remesas $8 \%$.

- Respecto al trabajo, el 34\% se desempeña en el empleo formal, el $31 \%$ en el trabajo temporario y el $25 \%$ en el comercio.

- Los tres problemas principales de acceso de salud que más de la mitad de los encuestados reportan son la falta de medicinas y personal médico en conjunto con el aumento de enfermedades en la comunidad.

\footnotetext{
${ }^{2}$ https://reliefweb.int/sites/reliefweb.int/files/resources/Venezuela\%20Crisis\%20SitRep September\%202020\%20\%282\%29.pdf,

${ }^{3}$ https://r4v.info/es/situations/platform
} 
- En cuanto a los alimentos se identifican problemas tanto de disponibilidad (37\% reporta que no hay alimentos) así como acceso ( $88 \%$ de los encuestados reportan que son muy caros).

Esta encuesta también cuenta con componentes de retroanálisis por parte de los hogares, donde una vez identificados los problemas, se les pide que sugieran posibles soluciones. Es importante mostrar que la mayoría de los hogares sugieren aumentar la entrega de alimentos, lo que puede estar sugiriendo una alta dependencia de la ayuda humanitaria para cubrir las necesidades, en vez de considerar oportunidades de empleo y otras mejoras de medios de vida.

Además, a la previamente deteriorada situación de medios de vida, hay que combinarla con los efectos perniciosos de la Pandemia global de COVID-19 que ha tenido en el población Venezolana. UNOCHA 4 reporta que, a principios de octubre, se contabilizan 83.137 casos positivos con 697 fallecimientos. La gran parte de los casos se concentran en los estados de Bolívar, Zulia, Amazonas y Delta Arnacuro. Sin embargo, se debe considerar que existe mucha limitación en la capacidad de diagnóstico, en especial en zonas de alta concentración de población indígena, por lo que estas cifras pueden estar bajo-reportadas.

El sistema de seguimiento del Banco Mundial sobre los ajustes en los programas sociales a raíz de la pandemia (Gentilini, et al, 2020), permite esquematizar las medidas tomadas por el régimen actual (Cuadro 1).

\section{Cuadro 1: Caracterización de medidas de protección social.}

Dimensión

Asistencia Social
Medida

Transferencias en efectivo

Aumento de las transferencias monetarias mensuales, más una transferencia única (que llega al $80 \%$ de la población), a través de programas existentes y pagada a través de la plataforma Sistema Patria (expansión vertical).

En especie

Servicios públicos y apoyo financiero
Incremento de las entregas de paquetes de alimentos subsidiados a través del programa CLAP.

- Pagos de alquiler residencial y comercial suspendidos por 6 meses (para empresas y personas afectadas por COVID19). Se reembolsará a los propietarios. Además, se prohíbe la desconexión del servicio por falta de pago por parte de las empresas de telecomunicaciones (televisión por cable, teléfono, teléfonos móviles, internet).

- El gobierno eximirá del impuesto sobre la renta a las personas con ingresos equivalentes a menos de tres salarios mínimos en 2019 (el impuesto sobre la renta de 2019 vence en marzo). Contribuyentes elegibles que ya habían declarado y pagado su el impuesto sobre la renta para el momento en que se anuncie la exención recibirá un crédito fiscal aplicable para los años siguientes.

${ }^{4}$ https://reliefweb.int/sites/reliefweb.int/files/resources/Informe\%20de\%20situaci\%C3\%B3n\%20-\%20Venezuela\%20\%20-

\%20Agosto\%202020\%20-\%2012\%20oct.\%202020.pdf 

ses (marzo a agosto), a través de la misma plataforma en línea utilizada para las transferencias sociales (plataforma Sistema Patria)

Fuente: Gentilini et al, 2020

Existen además varios esfuerzos de ayuda humanitaria coordinados en el campo. Se resalta el trabajo de coordinación entre la Cruz Roja, UNOCHA, Caritas y WorldVIsion ${ }^{5}$, que ha entregado ayuda en forma de efectivo, alimentos y servicios de salud. Especial atención se está llevando a cabo en lo que respectan a medidas sanitarias para prevención y tratamiento del COVID-19.

Mirando hacia los próximos meses, una preocupación central es que la ya deteriorada situación se transforme, por el manejo inadecuado de la pandemia y la falta de recursos, en una tragedia humanitaria aún mayor.

En lo que sigue se plantean algunas experiencias sobre programas de protección social y sus ajustes durante la pandemia, como insumos para un futuro programa de recuperación en Venezuela, reconociendo las limitaciones de lo que se analiza dadas las terribles condiciones actuales y la incertidumbre respecto del futuro.

\section{BREVE REVISION DE PROGRAMAS DE PROTECCIÓN SOCIAL EN ALC}

\section{a) Diferentes tipos de programas de asistencia social y gasto aso- ciado}

El Cuadro 2 presenta la clasificación de programas de protección social utilizada por la base de datos ASPIRE del Banco Mundial (exceptuando algunos programas del mercado laboral, que también se incluyen en la clasificación básica, pero son menos relevantes para la discusión en este trabajo).

Cuadro 2: Clasificación de Programas en la base ASPIRE

\footnotetext{
${ }^{5}$ https://reliefweb.int/sites/reliefweb.int/files/resources/Venezuela\%20Crisis\%20SitRep September\%202020\%20\%282\%29.pdf https://reliefweb.int/sites/reliefweb.int/files/resources/Informe\%20de\%20situaci\%C3\%B3n\%20-\%20Venezuela\%20\%20\%20Agosto\%202020\%20-\%2012\%20oct.\%202020.pdf

http://caritasvenezuela.org/wp-content/uploads/2020/09/BOLETIN-EPIDEMIOLOGICO-No-4-r-ABRIL-A-JUNIO-2020-ARISTAS-DELA-COVID-19_compressed-1.pdf
} 
ASISTENCIA SOCIAL
Pensiones Contributivas

Otros Seguros Sociales Transferencias incondicionales
de efectivo

Transferencias condicionales del efectivo.

Pensiones Sociales (non-contributivas)

Alimentos y transferencias en especie

Alimentación escolar

Obras públicas, trabajo y creación directa de empleo

Subsidios y Exenciones de impuestos/tasas
Pensión de vejez (todos los regímenes, nacional, funcionarios civiles, veteranos, otros especiales)

Pensión de supervivencia (todos los regímenes, nacional, funcionarios civiles, veteranos, otros especiales)

Pensión de invalidez (todos los regímenes, nacional, funcionarios civiles, veteranos, otros especiales)

Beneficios por lesiones laborales

Beneficios de licencia por enfermedad pagada

Salud

Beneficios de maternidad / paternidad

Transferencias de efectivo dirigidas a la pobreza y programas de último recurso

Asignación familiar / para niños / orfandad (incluidas las prestaciones para niños huérfanos y vulnerables)

Subsidios funerarios no contributivos, subsidios de entierro

Apoyo en efectivo de emergencia (incluido el apoyo a refugiados / migrantes que regresan)

\section{Caridad publica}

Transferencias de efectivo condicionadas

Pensiones sociales de vejez

Beneficios por discapacidad / beneficios no contributivos para víctimas de guerra

\section{Supervivencia}

Cupones de alimentos, raciones y vales

Programas de distribución de alimentos

Programas nutricionales (terapéutica, alimentación complementaria y PVVIH)

Apoyo en especie / no alimentario (material educativo, textos gratuitos y uniformes)

Alimentación escolar

Efectivo por trabajo

Alimentos por trabajo (incluidos alimentos para capacitación, alimentos para activos, etc.)

Exenciones de seguro médico y tarifas médicas reducidas

Exenciones de cuotas de educación

Subsidios alimentarios

Subsidios y asignaciones de vivienda (y "privilegios")

Subsidios y subsidios para servicios públicos y electricidad

Subvenciones a los insumos agrícolas

Beneficios de becas / educación

Servicios de asistencia social, traslados para cuidadores

Lo que queda fuera de las categorías anteriores 
Es necesario distinguir entre los programas de protección social no contributivos (que en la clasificación de ASPIRE se llaman "Asistencia social") de los sistemas de protección social contributivos (llamados Seguro social"). La diferencia es que los primeros se financian con recursos que provienen de rentas generales (es decir, lo beneficiarios no han aportado directamente a los fondos que reciben, de allí el nombre "no contributivo"), mientras que los otros programas son "contributivos," es decir que se supone que se financian principalmente con impuestos específicos sobre los salarios e ingresos de los propios beneficiados (aunque esto no siempre sucede en la práctica y muchos gobiernos suplementan los recursos de esos programas con ingresos de fuentes impositivas generales).

Las redes de protección social y los programas de transferencias de ingresos (condicionadas o no) son importantes para aliviar la pobreza y la inseguridad alimentaria. A la vez, expanden la demanda interna de los más pobres y vulnerables (que tienen mayor propensión al consumo en productos locales), en un ciclo virtuoso que puede sostener el crecimiento y el empleo nacional. Los sistemas de protección social contributivos ciertamente también contribuyen a mejorar las condiciones de pobreza e inseguridad alimentaria, pero por lo general en ALC tienen como beneficiarios a población con empleos formales que se encuentran en mejores condiciones que los segmentos informales. Este documento se centra en los programas no contributivos que atienden a los segmentos más pobres, y presenta algunas reflexiones para programas futuros similares en Venezuela, basado en la experiencia de ALC.

El Gráfico 1 muestra la estructura de programas de asistencia social y el gasto como porcentaje del PBI, comparando ALC con el promedio del resto de los países en desarrollo que están en la base de datos de ASPIRE (no incluyen las exenciones de tasas para servicios de salud, educación, etc.).

${ }^{6}$ The Atlas of Social Protection: Indicators of Resilience and Equity, World Bank Group, https://www.worldbank.org/en/data/datatopics/aspire 
Gráfico 1: Programas de Asistencia Social como \% del PBI

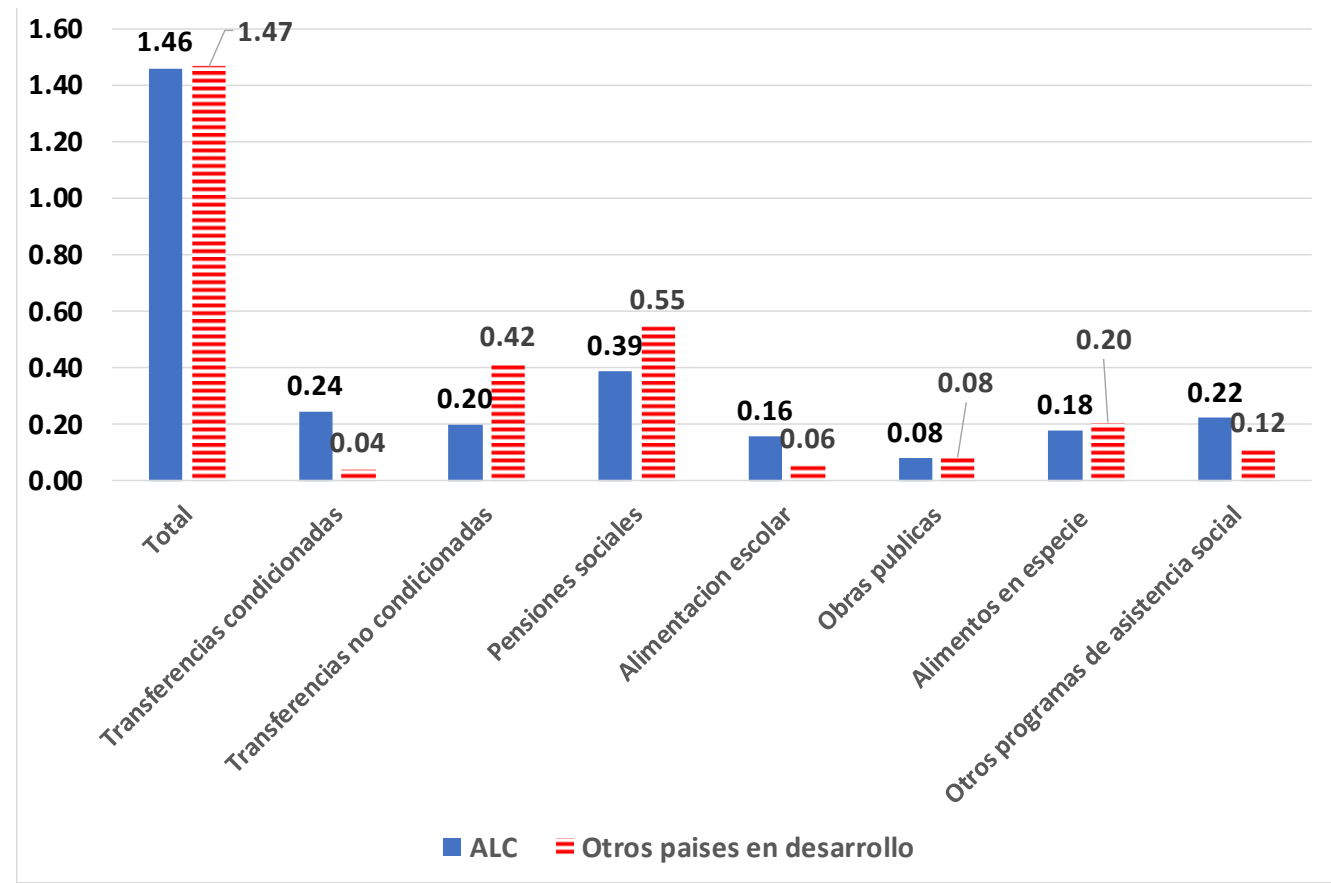

Fuente: autores con datos de ASPIRE

La región gasta en promedio (no ponderado, contando cada país individualmente) aproximadamente lo mismo que el resto de los países en desarrollo: alrededor de $1.5 \%$ del PBI. Hay también algunas diferencias en la estructura de la asistencia social: la región ha sido pionera en los programas de transferencias condicionadas (Stampini y Tornarolli, 2012; Vásquez Russi et al 2019; Takahashi, 2017), y también gasta más en alimentación escolar, casi lo mismo en programas alimentarios, pero menos en otros programas.

Pero hay importantes diferencias entre países. El Gráfico 2 muestra el gasto en asistencia social como porcentaje del PIB de varios países de la región. 
Gráfico 2: Asistencia Social (\% del PIB)

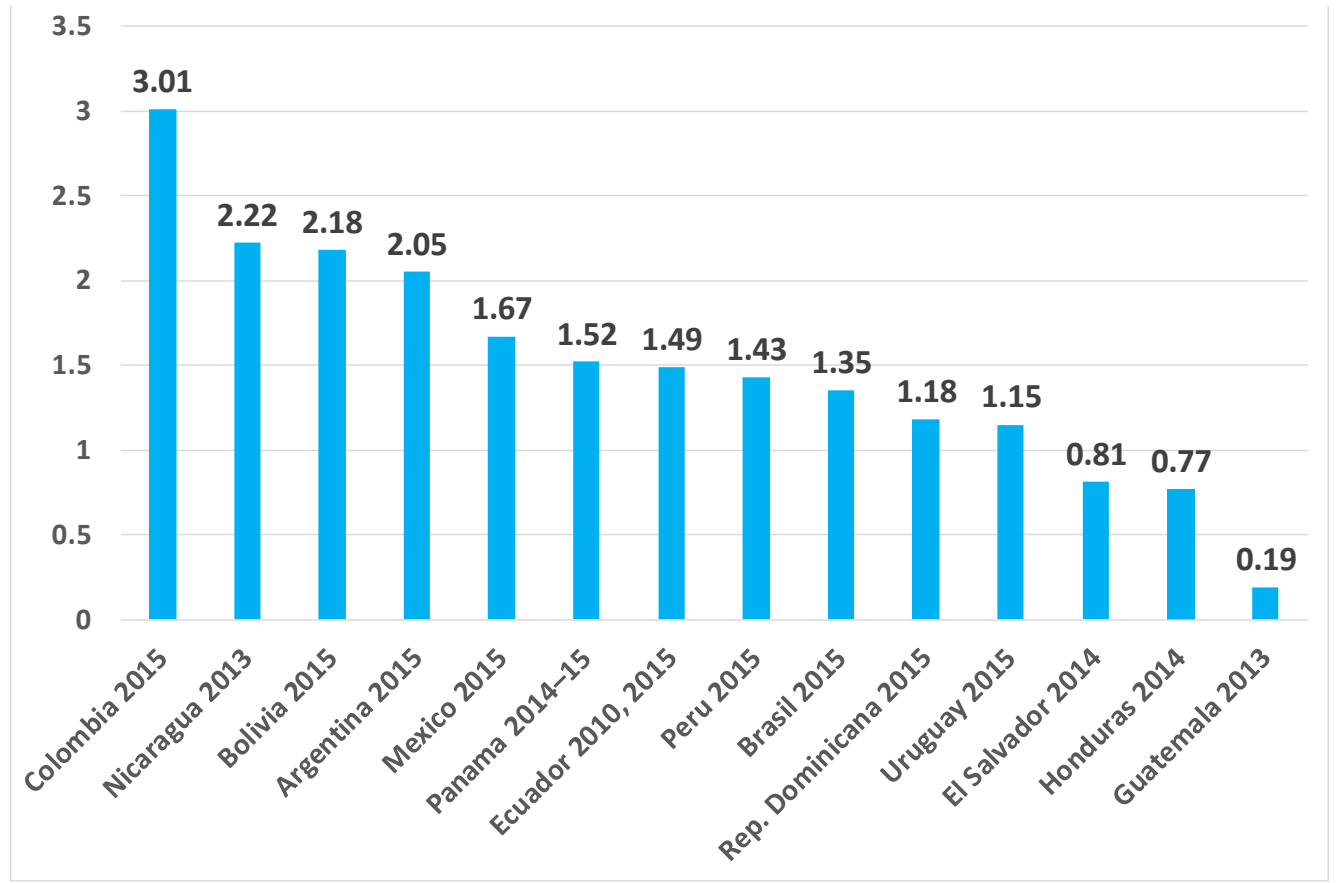

Fuente: ASPIRE,

Un tema central de diseño es el costo total de los programas de asistencia social. Por ejemplo, con los estimados de la UCAB mencionados antes, solamente el programa de lucha contra la pobreza costaría casi $1,4 \%$ del PBI (tomando el promedio del PBI de Venezuela entre 2000 y 2014, y no los valores deprimidos actuales).

Otro problema crucial, que está relacionado con el costo total, es la focalización de los programas. El Gráfico 3 presenta dos indicadores de la distribución por quintiles solamente del programa de transferencias condicionadas (PTC): el primer indicador es la incidencia de beneficiarios y se refiere a cómo se distribuyen el total de las transferencias en porcentaje de personas por quintil. Es decir, de todos los que reciben transferencias condicionadas, qué porcentaje de personas hay en cada quintil (tienen que sumar $100 \%$ con todos los quintiles). La incidencia de beneficios se refiere a cómo se distribuye el valor del total de las transferencias por quintil. Esto es, de toda la cantidad de dinero que se distribuyó en subsidios qué porcentaje de ese valor fue recibido por cada quintil (también tienen que sumar $100 \%$ con todos los quintiles). Los datos corresponden al promedio de los países para el último año en la base de datos (usualmente 2015-2016). 


\section{Gráfico 3: Incidencia en Beneficiarios y de los Beneficios (por quintil)}

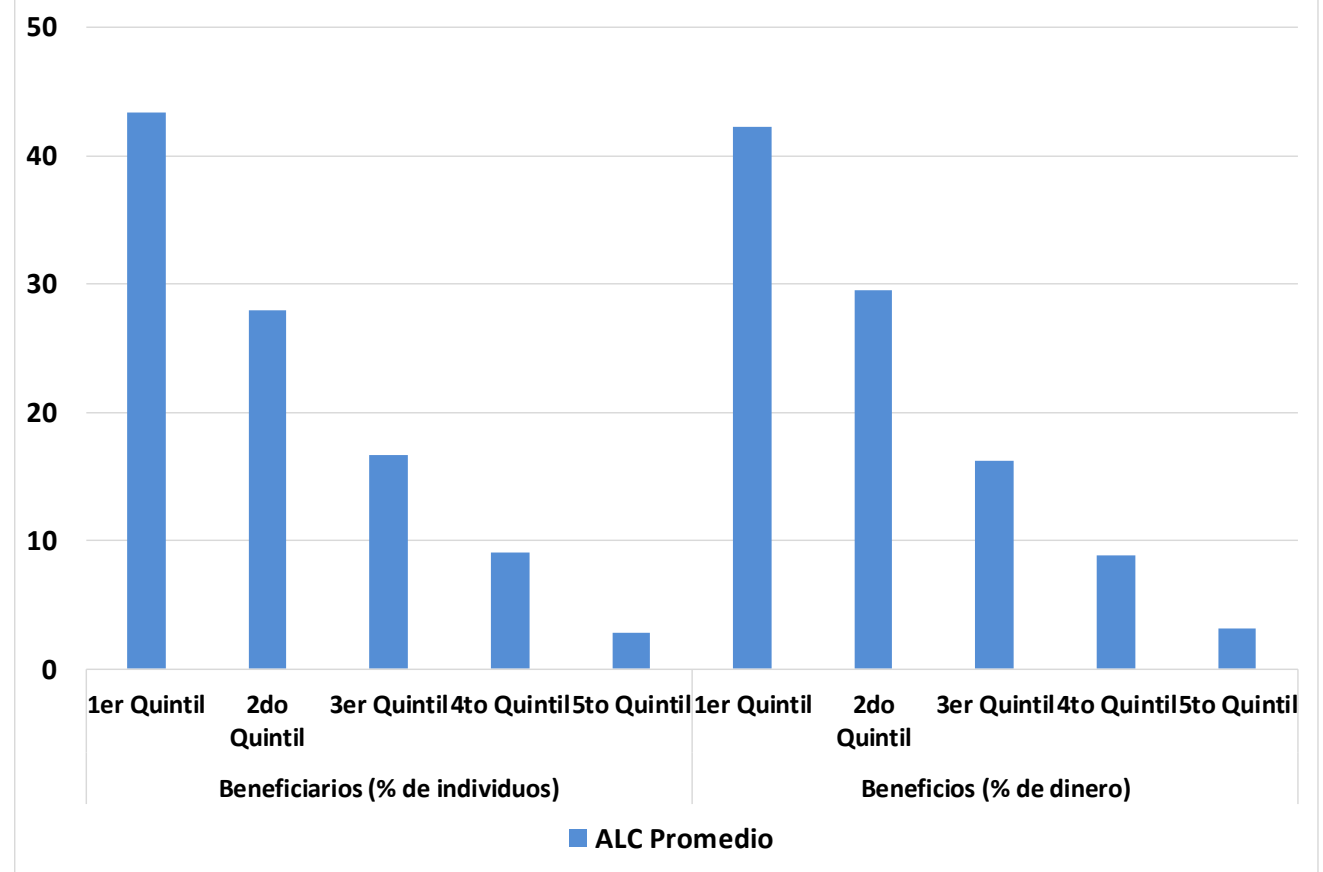

Fuente: ASPIRE

En promedio en ALC alrededor de $70 \%$ de los beneficiarios y de los beneficios corresponden a los dos quintiles más pobres, pero eso significa que un $30 \%$ de los beneficios y beneficiarios corresponde a los quintiles superiores, y en particular algo más del $10 \%$ corresponde a los dos quintiles más ricos. Esto indica problemas de focalización. Si se consideran otros programas de protección social, la focalización es aún menos adecuada: de acuerdo con ASPIRE la incidencia de todos los programas de asistencia social ${ }^{7}$ en el quintil más pobre es el $26 \%{ }^{8}$

Una mejor focalización permitiría ampliar la cobertura y reforzar los pagos a los más pobres (los últimos dos quintiles) sin aumento del gasto, y con un mayor impacto en la reducción de la pobreza y la desigualdad.

Por ende, cualquier programa futuro tiene que considerar a) el nivel de gasto y b) su focalización. El nivel de gasto futuro tendrá que ser considerado usando información actualizada al momento de la implementación, que considere 1) el número de pobres en ese punto en el tiempo; 2) la brecha de pobreza sin programas sociales de ningún tipo (es decir cuál es la diferencia entre el nivel promedio de ingresos de la población pobre sin transferencias y la línea de pobreza que se tome como referencia); y 3) los costos de focalización y administración.

\footnotetext{
${ }^{7}$ Nótese que el Gráfico 3 se refería solamente a los programas de transferencias condicionadas, mientras que en el texto se hace referencia a todos los programas del Cuadro 2 (más algunas intervenciones en el mercado laboral).

${ }^{8}$ Ver https://www.worldbank.org/en/data/datatopics/aspire/region/latin-america-and-caribbean.
} 
En las secciones que siguen discuten brevemente los siguientes tipos de intervenciones en ALC: 1) los programas de transferencias condicionadas (PTC); 2) los programas de alimentación escolar; y 3) una variedad de programas alimentarios que a su vez cubren diferentes modalidades de intervenciones. Cada uno de esos tipos de programas está discutido brevemente en una de las secciones siguientes.

\section{b) Programas de transferencias condicionadas ${ }^{9}$}

Los Programas de Transferencias Condicionadas (PTC) han tenido su origen en América Latina y el Caribe, empezando con iniciativas en México (el programa PROGRESA que fue puesto en marcha en la segunda mitad de los 1990s) (Fernald et al., 2008, y Levy y Rodríguez, 2005). Un objetivo principal es romper la cadena de transmisión de la pobreza, mediante las transferencias de dinero a las familias con la condicionalidad que los hijos/hijas vayan a la escuela, que accedan a ciertas prestaciones básicas de salud, y otros aspectos relacionados con la alimentación adecuada.

Estos programas se han extendido en la región en últimos 20 años en la región, y en la actualidad hay más de 30 programas activos ${ }^{10}$ (Cecchini y Atuesta, 2017). El Cuadro 3 muestra una lista de esos programas.

Cuadro 3: Programas de transferencias condicionadas en América Latina y el Caribe, según país y según si están operando o no, 1996-2015

\begin{tabular}{llc}
\multicolumn{1}{c}{ País } & \multicolumn{1}{c}{ Nombre del programa } & Año de inicio \\
\hline Argentina & $\begin{array}{l}\text { Asignación Universal por Hijo para Protección Social } \\
\end{array}$ & 2009 \\
& $\begin{array}{l}\text { Plan AlimentAR } \\
\text { Programa de Ciudadanía Porteña }\end{array}$ & 2019 \\
& Building Opportunities for Our Social Transformation & 2005 \\
Bolivia & & 2011 \\
(Est. Plur, de) & Bono Juancito Pinto & 2006 \\
Brasil & Bono Madre Niño-Niña Juana Azurduy & 2009 \\
& Programa Bolsa Familia & 2003 \\
& Programa bolsa Verde & 2011 \\
Chile & Programa de Erradicação do Trabalho Infantil & 1996 \\
& Chile Solidario/a & 2002 \\
& Subsistema de Seguridades y Oportunidades (Ingreso Ético & 2012 \\
Colombia & Familiar) & 2001 \\
& Más Familias en Acción & 2007 \\
\hline
\end{tabular}

\footnotetext{
${ }^{9}$ Esta sección y las dos siguientes se basan en Biermayr-Jenzano, 2020, que realizó una revisión de 13 PTCs en ejecución en 7 países de la región; 10 programas de alimentación en 9 países y los programas de alimentación escolar en marcha en 16 países de América Latina, Centroamérica y el Caribe.

${ }^{10}$ El detalle de los programas descriptos está referenciado en la base de datos de "Programas de protección social no contributiva en América Latina y el Caribe": https://dds.cepal.org/bpsnc/ptc
} 


\begin{tabular}{|c|c|c|}
\hline Costa Rica & Avancemos & 2006 \\
\hline Ecuador & $\begin{array}{l}\text { Bono de Desarrollo Humano } \\
\text { Desnutrición Cero }\end{array}$ & $\begin{array}{l}2003 \\
2011\end{array}$ \\
\hline El Salvador & Programa de Apoyo a Comunidades Solidarias en El Salvador & 2005 \\
\hline Guatemala & Mi Bono Seguro & 2012 \\
\hline Haití & Ti Manman Cheri tou nef & 2012 \\
\hline Honduras & Bono Vida Mejor & 2010 \\
\hline Jamaica & Programme of Advancement through Health and Education & 2001 \\
\hline México & Prospera & 2014 \\
\hline Panamá & $\begin{array}{l}\text { Red de Oportunidades } \\
\text { Bonos Familiares para la Compra de Alimentos }\end{array}$ & $\begin{array}{l}2006 \\
2005\end{array}$ \\
\hline Paraguay & $\begin{array}{l}\text { Tekoporã } \\
\text { Abrazo }\end{array}$ & $\begin{array}{l}2005 \\
2005\end{array}$ \\
\hline Perú & Juntos & 2005 \\
\hline $\begin{array}{l}\text { República Domini- } \\
\text { cana }\end{array}$ & Progresando con Solidaridad & 2012 \\
\hline Trinidad y Tobago & Targeted Conditional Cash Transfer Program & 2006 \\
\hline Uruguay & $\begin{array}{l}\text { Asignaciones Familiares - Plan de Equidad } \\
\text { Tarjeta Uruguay Social }\end{array}$ & $\begin{array}{l}2008 \\
2006\end{array}$ \\
\hline
\end{tabular}

Fuente: Biermayr-Jenzano, 2020.

Se estima que los PTC cubrían un quinto de la población en 2015, alrededor de 132 millones de personas y 30 millones de hogares, con una inversión de 153 dólares per cápita (Cecchini y Atuesta, 2017, y Biermayr-Jenzano, 2020).

Los PTC han introducido modelos innovadores de gestión usando medios electrónicos para el registro de beneficiarios y para la ejecución de los programas (Cecchini, 2013) lo que ha facilitado el seguimiento y la evaluación de estos programas. Se considera que una de las principales contribuciones de los PTC está centrada en reorientar la protección social principalmente hacia la infancia y su desarrollo humano buscando disminuir la pobreza en el corto plazo por medio de las transferencias monetarias directas o el acceso a alimentos que permiten sostener niveles básicos de consumo para toda la familia, y en el largo plazo, a través de las mejoras en los niveles de salud y educación de niños y niñas de hogares en situación de pobreza (Biermayr-Jenzano, 2020).

Diferentes evaluaciones (Adato y Hoddinott, 2010; World Bank, 2018) han encontrado impactos favorables en la reducción de la pobreza y la desigualdad. Pero, por otro lado, no está claro que hayan mejorado la nutrición en sentido amplio, más allá de haber permitido acceso al consumo de mayores niveles de calorías. Los PTC deben evolucionar hacia promover y facilitar una alimentación accesible y adecuada no solamente en relación con el valor calórico sino de otros nutrientes claves para la salud y el desarrollo de los grupos vulnerables. 
Es de destacar que si bien la gran mayoría de los programas incluidos en el trabajo de Biermayr-Jenzano (2020) tienen objetivos relacionados con mejorar la calidad de la alimentación del publico carenciado, en muchos casos no existen guías estandardizadas o de referencia respecto de alimentos nutritivos y variados, y las regulaciones se centran en prohibiciones sobre la adquisición de licor o cigarrillos con los váuchers o transferencias monetarias. Además, la operacionalización de los programas para que las familias compren productos saludables no es clara, incluyendo la carencia de registros, controles o mecanismo de seguimiento para asegurar que se compren productos saludables (Biermayr-Jenzano, 2020).

Por otra parte, algunos de esos programas consideran opciones de compras locales (mercados y ferias) (FAO, 2013) para así estimular la economía local, lo que también puede tener efectos favorables sobre la alimentación.

Cómo en otras medidas de política, la buena focalización es fundamental para disminuir los costos y potenciar los efectos en la población que sufre carencias. Al momento, no existe información detallada para determinar si los niveles actuales de transferencias son los adecuados para ayudar a salir de la pobreza. Estos programas, por otro lado, no deben tener condicionalidad política partidaria (como parece suceder con la politización actual de las CLAP en Venezuela) para ser equitativos y eficientes, y cubrir a toda la población que se encuentre dentro de los requisitos definidos.

Un paso adicional a los PTC sería considerar el Ingreso Básico Universal (IBU), o variaciones de este tema (como fue el caso del "impuesto negativo sobre la renta"11 discutido hace varios años en EEUU y que diera origen a una versión mucho más limitada en el Earned Income Tax Credit, EITC). Estos enfoques están siendo considerados en los últimos años como una herramienta posible bajo los programas de transferencias. En este caso, la asignación es universal, alcanzando a todos los hogares, y por tanto no habría condicionalidad. Las principales críticas han sido el posible costo asociado ${ }^{12}$ y el debilitamiento de los incentivos laborales.

Varios países, tales como EEUU y Brasil, están utilizando esquemas de este tipo para atender la grave crisis social de la pandemia, aunque se trata de programas acotados en el tiempo.

\section{c) Programas de alimentación escolar.}

Una herramienta empleada a lo largo del continente para el apoyo alimentario a los niños de sectores de bajos recursos es la distribución de alimentos mediante comedores escolares. Estos programas han sido implementados en la región desde hace bastante tiempo: por ejemplo, en Colombia, se están llevando a cabo desde 1945, y, Paraguay, que tiene uno de los programas más recientes ya lleva más de 25 años de ejecución.

\footnotetext{
${ }^{11}$ El "impuesto negativo sobre la renta" es una forma de proporcionar dinero a las personas por debajo de cierto nivel de ingresos. Las personas pagan impuestos de acuerdo con la escala aplicada, pero si tienen ingresos por debajo de cierto nivel, entonces reciben pagos del gobierno para alcanzar el ingreso mínimo definido.

${ }^{12}$ Aunque se ha argumentado que el incremento neto en el gasto no sería tan alto considerando que el IBU reemplazaría todos los otros programas, bajaría los costos administrativos totales, y que las personas deberían pagar impuestos a los ingresos incluyendo el IBU.
} 
Estos programas son un componente crítico para la lucha contra la malnutrición, y constituyen la red de protección social más amplia a nivel mundial (WFP, 2017). En la región, el 92\% de los niños se encuentran matriculados en instituciones educativas primarias, y, por lo tanto, la distribución de alimentos en las escuelas, que abarca unos 85 millones de niños y niñas, tiene el beneficio de alcanzar a casi todos los que están en riesgo de malnutrición (WFP 2017). Estos programas mejoran el nivel nutricional del casi $12 \%$ de los niños y niñas en la región que sufren de malnutrición crónica (WFP 2017).

Existe sin embargo gran diversidad en el diseño e implementación de los programas de comedores escolares, en términos de su cobertura y calidad. De todas maneras, este tipo de intervenciones tienen la ventaja sobre otro tipo de modalidades alimentarias de, al menos en teoría, brindar una dieta balanceada (al ser diseñados por nutricionistas y personal de la salud) y, además, al ser de distribución diaria, es de periodicidad recurrente y constante. El incluir la dimensión alimentaria dentro de la institución educativa facilita la escolaridad de los niños, al ser un incentivo para atender a las escuelas y ayudarles a prestar mayor atención a las clases al estar mejor alimentados.

En varios casos, las escuelas también se han convertido en un punto de distribución de alimentos para las familias, extendiendo los programas alimentarios de las escuelas hacia los hogares. Otros programas se han articulado con la economía local al comprar alimentos a productores locales, permitiendo un segundo efecto positivo de su implementación. Las principales limitaciones son que los programas de alimentación escolar por lo general solamente cubren el desayuno y el almuerzo (si es que cubren ambos), y funcionan solamente durante el año escolar (9 meses), dejando un vacío de varios meses al año hasta el inicio del próximo año escolar.

El Anexo 1 presenta una lista de programas de alimentación escolar desarrollados e implementados actualmente en varios de los países de América latina y el Caribe (usando las descripciones y cifras publicadas en la base de datos de la Plataforma de Seguridad Alimentaria y Nutricional (PSAN) de la Comunidad de Estados Latinoamericanos y Caribeños, (CELAC), la base de datos NOURISHING Framework ${ }^{13}$ y también mediante la revisión documental de los programas detallados en los correspondientes sitios web de los gobiernos de los respectivos países cuando estos estuvieran vigentes).

Según datos de la base ASPIRE, en ALC, el promedio de gasto en comedores escolares como porcentaje del PBI es de 0,16\%, similar al promedio mundial. Sin embargo, tal como muestra el Gráfico 4, existe una amplia variedad entre los países considerados.

\footnotetext{
${ }^{13}$ NOURISHING framework: http://www.wcrf.org/int/policy/nourishing-framework
} 


\section{Gráfico 4: Gastos en Comedores Escolares (\% PBI)}

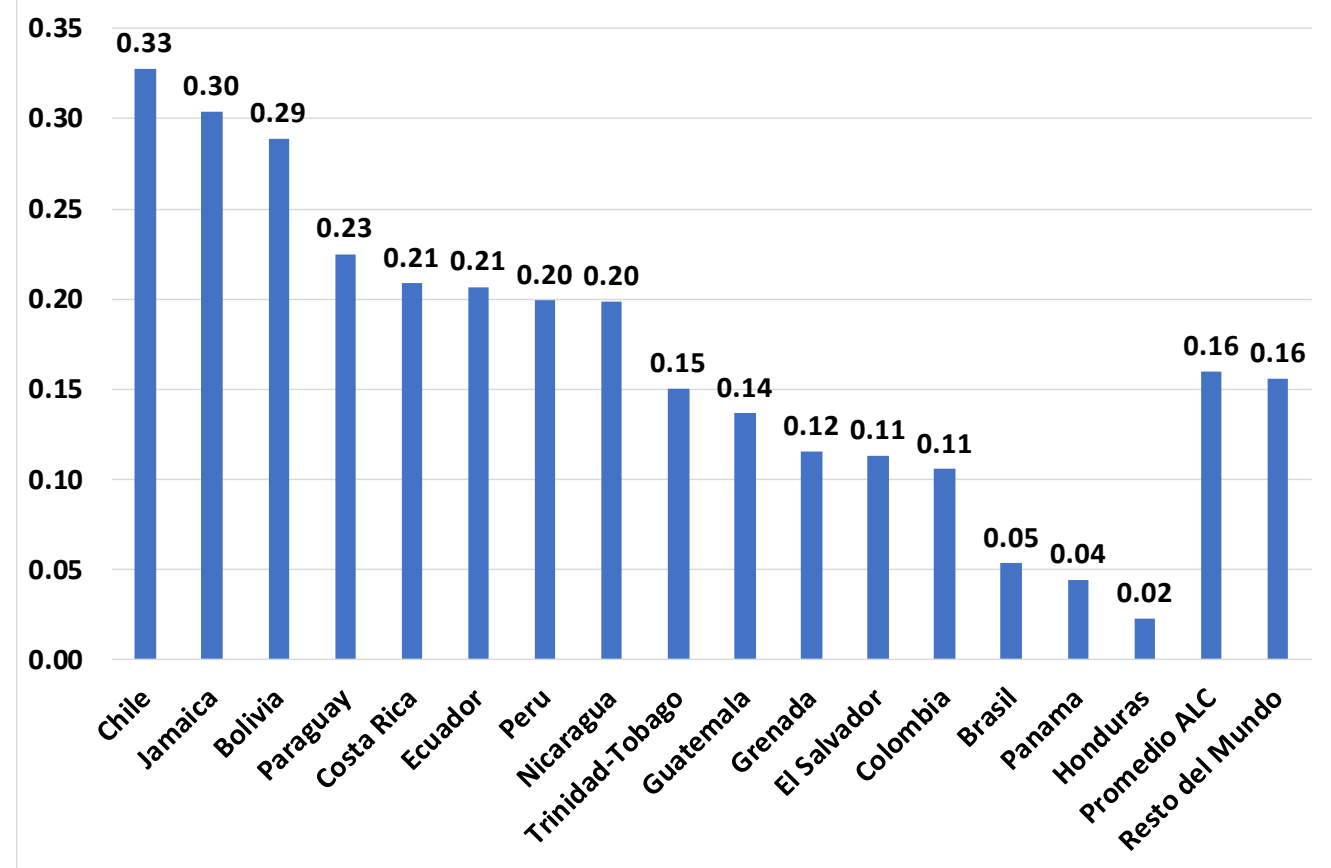

Fuente: Autores con datos de ASPIRE

Durante la pandemia, y con el cierre de las escuelas, varios de estos programas se han reconvertido en mecanismos de distribución de comidas diarias o semanales, para los estudiantes participantes y sus familias.

En este marco, es de interés considerar que, en Venezuela, la matrícula escolar ha caído 1,7 millones de niños ( de 12,7 a 11 millones), y sólo el 60 por ciento de los mismos va regularmente a la escuela (Departamento de Estado de los Estados Unidos, 2020). Esto es un limitante importante a considerar a la hora de planificar una intervención basada en la escuela, aunque cabe destacar que, anecdóticamente, muchos de los niños no van a la misma por falta de transporte y alimentos. En este caso, ofrecer alimentos en los establecimientos escolares podría constituir un incentivo para los niños para continuar con su educación.

\section{d) Otros programas alimentarios}

El Gráfico 5 muestra el gasto en otros programas alimentarios en ALC como porcentaje del $\mathrm{PBI}$, de acuerdo a la clasificación y datos de ASPIRE del Banco Mundial. La región gasta menos de la mitad del promedio de los otros países en desarrollo incluidos en la base de datos de ASPIRE. También acá existen diferencias en los niveles de gasto entre países, y también hay una amplia variedad de modalidades de intervención. 


\section{Gráfico 5: Programas Alimentarios (\% PBI)}

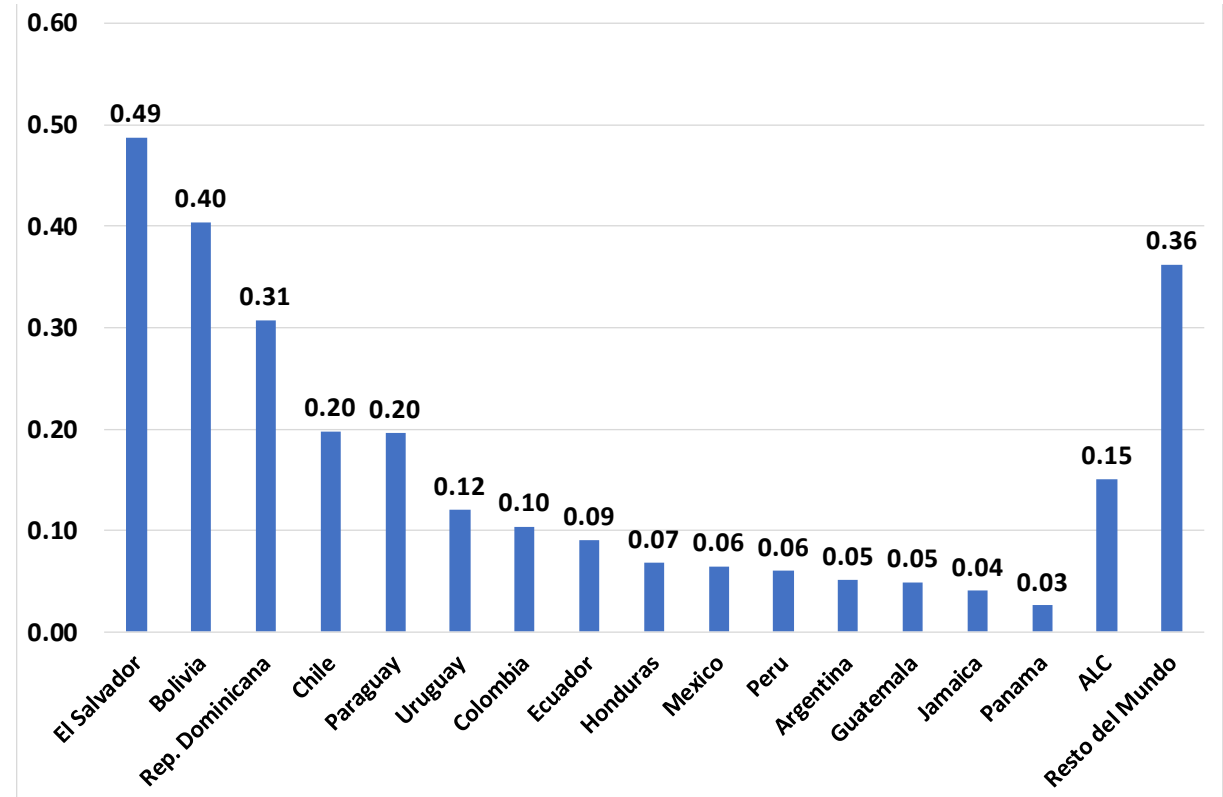

Fuente: Autores con datos de ASPIRE

Estos programas pueden ser separados o ser parte de otras intervenciones, como los PTC (y en otros países en desarrollo, pero no tanto en ALC, con esquemas de alimentos a cambio de trabajo en obras públicas).

También varían mucho en términos de su diseño en las dimensiones mencionadas a continuación:

- La población atendida, por ejemplo, infantes (de 0 a 5 años), adolescentes y jóvenes, mujeres gestantes, ${ }^{14}$ personas de la tercera edad, ${ }^{15} \mathrm{u}$ otros grupos considerados vulnerables;

\footnotetext{
${ }^{14}$ El caso de PROCOMIDA, de Guatemala fue un programa de asistencia a la seguridad alimentaria, la salud materno-infantil de mujeres embarazadas o lactantes y de la alimentación para niños/as de $0-24$ meses en situación de inseguridad alimentaria aguda en la zona norte de Guatemala (Leroy, Olney, and Ruel, 2019). El programa ofrecía una serie de beneficios que incluyeron transferencias alimentarias para disminuir la inseguridad alimentaria local, atención de los problemas de desnutrición mediante la provisión de raciones nutritivas, las que se componían de una mezcla de maíz y soya, arroz en bolsas, frijoles pintos y aceite vegetal. La estrategia de implementación también incluyó el desarrollo de la capacidad para que las madres y personal de cuidado pudieran adoptar prácticas más saludables y también propiciar un cambio de actitud positivo en cuanto a la salud. Otro ejemplo es el "Bono Madre Niña-Niño Juana Azurduy" en Bolivia que reciben el llamado Subsidio Prenatal para La Vida, diseñado para ofrecer cobertura a las mujeres embrazadas entre el 5ำ y el 9ำ mes de gestación y niños menores de dos años que no puedan acceder a seguros de salud con el fin de reducir la desnutrición crónica y los niveles de mortalidad materna e infantil. Este bono ofrece, además de los beneficios normales de las transferencias condicionadas, un suplemento de alimentos mediante el acceso a Canastas alimentarias (Biermayr-Jenzano, 2020)

${ }^{15}$ Un ejemplo es el de las "Canastas Alimentarias para Adultos Mayores" en México parte del Programa Desarrollo Social Familias Fuertes Apoyo a Personas Adultas Mayores (funciona con la entrega de canastas alimentarias y servicios para apoyar a personas de 60 años de edad en adelante; pero no existe una determinación detallada de los productos que componen las canastas o los aspectos nutritivos de las mismas) (Biermayr-Jenzano, 2020).
} 
- Los objetivos alimentarios, que pueden ir de desnutrición por falta de calorías, o abarcar otros aspectos de dietas saludables y nutritivas, ${ }^{16}$ incluyendo preocupaciones por el sobrepeso y la obesidad;

- $\quad$ Alcance (nacional, regional, local);

- Los instrumentos y medios de operación, que pueden incluir i) transferencias en especie (cajas de comidas); ii) tarjetas o cupones alimentarios; iii) simplemente dinero con el destino de compra de alimentos; iv) operar en espacios definidos (como comedores comunitarios ${ }^{17}$ ); v) ser mecanismos de compras colectivas de familias; ${ }^{18}$ o vi) sistemas públicos de venta de alimentos subsidiados ${ }^{19}$

- Su articulación o no con la producción local (es decir si hay requerimientos de compras a productores locales, o si son parte de programas agropecuarios de producción, ${ }^{20}$ incluyendo por ejemplo huertas comunitarias o en hogares $^{21}$ ).

Los anteriores programas consideran principalmente el consumo de alimentos. Otros se centran en la producción de alimentos. Uno de los varios casos en ALC es el programa ProHuerta en Argentina, ${ }^{22}$ que ya tiene 30 años de operación, enfocado principalmente a pequeños productores de subsistencia. Está implementado a través del Instituto Nacional de Tecnología Agrícola (INTA) y cuenta con la distribución de semillas para cubrir las diversas necesidades alimentarias de una familia, incluyendo calendario e instrucciones de siembra.

El programa distribuye semillas de distintas especies (granos y hortalizas) para ayudar con la seguridad alimentaria. El programa también apoya a los pequeños productores a comercializar sus excedentes.

\footnotetext{
${ }^{16}$ Ejemplos de programas con objetivos de dietas saludables y no solamente incremento de calorías incluyen el "Sistema Elige Vivir Sano" de vigencia en Chile y el Sistema Alimentario Sostenible para una Alimentación Saludable y la estrategia de "Sabores y Saberes" en Uruguay (Biermayr-Jenzano, 2020, Ministerio Secretaria General de Gobierno, Chile, 2008,Gobierno de Uruguay, 2019).

${ }^{17}$ Un caso son los Comedores Populares en Perú "COCINANDO PARA LA SALUD." Existen alrededor de unos 19,000 comedores populares en los municipios de todo el país; son organizados por los gobiernos locales y consisten en grupos de madres organizadas en cuanto a la compra, preparación y distribución de alimentos, que se venden a precios accesibles en la localidad (BiermayrJenzano, 2020).

18 Por ejemplo, las “Canastas Solidarias” en Ecuador (Biermayr-Jenzano, 2020; Garcés y Kirwan, 2009; Howe, 2008).

${ }^{19}$ Por ejemplo, México ha operado desde 1972 una cadena pública de más de 27,000 tiendas en todo el país (DICONSA), que proporcionan alimentos básicos y otros bienes esenciales a precios subsidiados a la población rural y urbana marginal, llegando a más de 47 millones de personas. Las tiendas son abastecidas por una red de almacenes centrales y regionales y varios miles de camiones de reparto para llegar incluso a las áreas más remotas. Este programa se complementa, a partir de 1995, con otro denominado LICONSA que provee leche fortificada subsidiada a más de 8 millones de beneficiarios vulnerables en todo el país (http://www.fao.org/3/a-i6006e.pdf).

20 Tal como el Programa Productivo Alimentario en Nicaragua (Social Protection 2017, Ministerio de Agricultura Familiar y Comunitaria de Nicaragua, 2017), que opera con un bono que brinda también acceso a herramientas para mejorar la eficiencia del trabajo rural, semillas, insumos, etc. Se espera que contribuya al desarrollo económico y el suministro interno de alimentos. Las mujeres de la unidad familiar son las beneficiarias directas, quienes además tienen chequeos prenatales en caso de embarazo. También tiene la condicionalidad como los PTC de asegurar la asistencia de los niños y niñas a controles médicos regulares asegurando también su participación en programas escolares (Biermayr-Jenzano, 2020).

${ }^{21}$ Como las llamadas "Cajas Urbanas" de Honduras, que en realidad fue un programa alimentario que tuvo como principal objetivo el fortalecimiento de huertos de agricultura urbana y periurbana (Biermayr-Jenzano, 2020).

22 http://prohuerta.inta.gob.ar/
} 
Este tipo de programas también se puede articular con la producción y comercialización de alimentos economía solidaria, social y popular, el cooperativismo y la agricultura familiar (Collin Harguindeguy, 2014). Sin embargo, es necesario para ello invertir y facilitar las organizaciones de agricultura familiar para que mejoren los procesos de producción, organización, e inocuidad. Esto permitiría aumentar la oferta de los alimentos saludables y vincularlas a los procesos de compras públicas para comedores escolares y comunitarios. Sin embargo, para garantizar el éxito de este tipo de esfuerzos, es necesaria una buena capacidad organizativa, acceso al financiamiento, facilitación para el cumplimiento de certificaciones y del aumento sostenible de producción de alimentos saludables y mayor rentabilidad económica.

Es fundamental, sin embargo, tener en cuenta la gran variabilidad de situaciones en las que se encuentran los productores agrícolas, por ende, considerar que se pueden llegar a necesitar distintos programas articulados entre sí, con distintas poblaciones específicas. Es así como puede que población en territorios rezagados (tales como la Amazonía en Venezuela) requieran esfuerzos diferentes, considerando distintos sistemas de producción.

Cualquier esfuerzo para mejorar la seguridad alimentaria de los hogares debe estructurarse alrededor de desarrollar entornos alimentarios saludables, lo que implica articulación de distintas instituciones gubernamentales relacionadas con los ámbitos de Salud, Producción y Agricultura. Este tipo de enfoques es complejo dado que se requieren simultáneamente análisis de competitividad de cadenas productivas, la expansión de la oferta suficiente y diversa de alimentos buen perfil nutricional (alimentos a promover); el acceso económico a estos alimentos, la puesta en marcha y empoderamiento para un buen uso del etiquetado frontal y medidas de educación nutricional.

Dada la enorme variedad de estos programas, un tema central desde la perspectiva de políticas públicas es evitar la duplicación de actividades y la proliferación de programas con bajo impacto. 


\section{ALGUNAS REFLEXIONES SOBRE PROGRAMAS DE PROTECCIÓN SOCIAL Y AYUDA ALIMENTARIA}

Las secciones anteriores analizaron tres modalidades de protección social con componentes de alimentación saludable: los programas de transferencia condicionada (PTC), los programas de alimentación escolar, y una variedad de programas alimentarios desarrollados en ALC. En general esos programas conforman una compleja red de servicios que tienden a proporcionar alimentos, acceso a salud y trabajo a las poblaciones bajo el nivel de pobreza.

A continuación, se presentan algunas consideraciones relacionadas con el diseño de programas de asistencia social para Venezuela en un futuro con la gobernanza democrática normalizada.

\section{a) Consideraciones generales: estrategia de desarrollo y estabili- dad macroeconómica}

Los programas de asistencia social no son substitutos de una estrategia de desarrollo y de un programa macroeconómico que asegure crecimiento con empleo y sin crisis recurrentes. Venezuela tiene que salir de su largo ciclo de crisis y estancamiento, y diversificar su estrategia de desarrollo eliminando su dependencia del petróleo, producto que de todas maneras va a ir perdiendo su papel en la economía mundial.

La terrible crisis que está sufriendo el país, ha sido agravada aún más por la pandemia, que ha profundizado los problemas de un sistema socioeconómico desigual. En el corto plazo y mediano plazo cualquier análisis tiene que reconocer que existe mucha incertidumbre respecto de la evolución de la pandemia. Por ello, las observaciones que siguen deben ser consideradas como preliminares.

\section{b) Análisis de políticas públicas}

El proceso de definición, implementación y control de las políticas públicas requiere responder una serie de preguntas (Díaz-Bonilla, 2015).

- $\quad$ Primero, hay que definir el problema que se quiere resolver y cuantificar su importancia.

- Segundo, hay que determinar por qué es necesaria la intervención pública para resolverlo, y si el gobierno puede intervenir adecuadamente. 
- Tercero, se deben definir objetivos cuantitativos o verificables en el tiempo, respondiendo a la pregunta "¿qué significa "resolver el problema"?

- Cuarto, hay que formular una o varias hipótesis sobre las razones del problema, y una "teoría del cambio" que explique cuáles son las posibles estrategias, enfoques, intervenciones e instrumentos que llevarían a los impactos y efectos esperados (es decir a aquellos resultados que "resolverían el problema").

- La quinta pregunta tiene que ver con cuáles serían los arreglos institucionales, de personal y presupuestarios necesarios para llevar adelante las intervenciones consideradas. En particular, hay que considerar las posibles fallas de gobierno en sus distintos niveles e instituciones, que pueden impedir su diseño e implementación.

- Sexto, se necesita un plan de implementación que defina qué hacer (actividades específicas, más allá de términos genéricos como "coordinación", articulación", etc.); quién lo hará (no puede haber actividades sin ejecutores responsables); cuándo (calendario); cómo (aspectos operativos, organizativos y tecnológicos); y con qué (presupuesto, personal, otros recursos).

- Finalmente, se necesitan mecanismos de monitoreo y evaluación.

Obviamente esos pasos y preguntas están en muchos casos relacionados y no pueden abordarse linealmente.

Con este marco conceptual se presentan a continuación algunas reflexiones sobre 1) Grupos objetivo y resultados buscados; 2) Programas e instrumentos; 3) Costos; 4) Programación e implementación; y 5) Monitoreo y evaluación.

\section{c) Grupos objetivo y resultados buscados}

El punto de partida es cuál es el grupo que se quiere atender, y por qué (es decir la definición del problema que se quiere resolver). Obviamente, en el caso de Venezuela, como lo muestran los trabajos de la UCAB mencionados, hay un serio problema de pobreza y está generalizado, lo que también conlleva graves carencias alimentarias.

Hay varias maneras de identificar las personas o familias que deben ser atendidas y cuantificar el problema. Uno es tomar como referencia aquellos venezolanos que estén bajo la línea de pobreza extrema o de indigencia, que en principio también considera el tema de alimentación, ya que esa línea refleja el costo de la canasta mínima de alimentos para satisfacer los requerimientos calóricos de una persona. La línea de pobreza total (extrema y no extrema) se construye añadiendo a esa línea un porcentaje para cubrir otras necesidades básicas. La fuente de datos son las encuestas de hogares de ingresos y gastos. 
Otra metodología de identificación de la población objetivo es usar el indicador FIAS (Food Insecurity Access Scale Indicator) desarrollado por la FAO, que se basa en encuestas de hogares acerca de evaluaciones subjetivos de acceso o carencia de alimentos. ${ }^{23}$

Finalmente, otra opción es la identificación mediante indicadores antropométricos (como peso relacionado con altura y edad), mortalidad/morbilidad, o de adecuación de la ingesta de vitaminas, minerales, proteínas, y similares, que suelen ser en general guías más precisas de la situación alimentaria de la población, pero tienen altos costos asociados para su implementación. La Oficina para la Coordinación de la Ayuda Humanitaria de las Naciones Unidad (UNOCHA en inglés) reporta que, a julio de 2020, 4\% de los niños menores de 5 años presentan desnutrición aguda global, con casi el 1\% siendo desnutrición aguda severa (UNOCHA, 2020).

Si el objetivo de un programa fuese lograr que toda la población se coloques por encima de la línea de indigencia (como manera de asegurar que todos tienen le ingreso mínimo para comprar la canasta alimentaria básica de alimentos), las preguntas a realizar a la hora de diseñar un programa efectivo, serían a) cuál es porcentaje de población por debajo de la línea de indigencia (estimado en un $61 \%$ según la UCAB,); y b) cuál es la "brecha de pobreza" (esto es, cuánto le falta al ingreso del indigente para alcanzar el valor de la canasta básica alimentaria). La respuesta a esas dos preguntas debería compararse con la cobertura actual de los planes de asistencia implementados y con el valor de las prestaciones disponibles, para poder definir qué es lo que falta.

Por otra parte, si el objetivo fuera cubrir solamente a niños/as y adolescentes, habría que hacer el mismo ejercicio, pero limitándose al porcentaje de la población de entre 0 y 17 años edad que se encuentran en situación de indigencia. Este porcentaje dentro de la subpoblación, se espera que sea mayor que para la población total (WorldVision 2020 reporta que los menores de 17 años representan el 40\% de la población).

Este ejercicio de cuantificación debería ser complementario de los necesarios para dimensionar programas concurrentes como comedores escolares y programas de atención materno-infantil, a la vez de asegurar coordinación y complementariedad entre ellos.

No obstante lo mencionado anteriormente, y dado el amplio espectro de la población en condiciones de necesidad económica, quizás no quede otra alternativa que pensar en un programa generalizado, tal como el IBU o variaciones del mismo. Pero si se opta por una focalización más direccionada, entonces encuestas como la ENCOVI serán de gran utilidad para identificar los grupos objetivos.

\footnotetext{
${ }^{23}$ La FAO usa una metodología diferente para cuantificar el número de población desnutrida, basada en los promedios de calorías disponibles por países, las necesidades mínimas de esa población (considerando la estructura de edades y género), y usando estimaciones de la distribución del ingreso. Esto permite estimar el número de personas que estarían desnutridas, pero no sirve para identificar personas o familias individuales.
} 


\section{d) Programa e instrumentos}

Cuando se diseña un programa, es fundamental tener claridad sobre los programas e instrumentos a emplear para su implementación. Ellos deben ajustarse a la situación socioeconómica del país, teniendo en cuenta cuál es la población objetivo y dónde se encuentra, y las posibles carencias a cubrir.

Por ende, la elección de programas e instrumentos va de la mano de la identificación del objetivo, caracterización adecuada de la población vulnerable, reconocimiento de posibles externalidades y costos asociados a la implementación.

Si el programa principal va a ser la entrega de dinero (como en el caso de los programas de transferencias condicionadas), un instrumento a considerar es el uso de tarjetas de débito/crédito, que además de hacer más transparentes los mecanismos de distribución, ayudan con la inclusión financiera de las familias. Pero si se usa un mecanismo que principalmente se administra digitalmente, hay que definir cómo se trabajaría en zonas rurales y otras sin acceso a oficinas bancarias y cajeros automáticos. En particular la población rural pobre puede requerir un programa especial (esto se discute en una sección separada). Además, de consideraciones respecto a la bancarización de la población, es importante considerar el alcance del sistema de distribución eléctrico para la operativización de este tipo de programas. Si el mismo no es confiable y presenta continuas fallas, los puntos de venta electrónico se vuelven ineficientes y poco fiables, limitando el uso real de este método de distribución.

Por su parte, si se trata de programas de apoyo a la alimentación, hay que considerar la discusión acerca de si es mejor la entrega de dinero, de tarjetas alimentarias, ${ }^{24}$ vales/cupones ("vouchers" en inglés) o distribución física de alimentos (y esto último es supuestamente el mecanismo del CLAP). La entrega de dinero tiene menos costos administrativos y les da más flexibilidad a las familias, pero es más difícil asegurar que esos recursos se asignen a dietas saludables (Hidrobo et al, 2014).

En el otro extremo, la distribución física de alimentos tiene mayores costos y desperdicios, y existe una mayor probabilidad de desvío de los alimentos hacia usos y grupos no priorizados. A la vez, es usual que se distribuyan productos por su contenido de energía (tales como harinas, aceites y azúcares), pero no necesariamente de alta calidad nutricional en su conjunto (por ejemplo, productos animales, frutas y hortalizas). En el medio de ambos sistemas, las tarjetas y los vales/cupones tienen costos más manejables y pueden controlar mejor la calidad nutricional de los alimentos

En todo caso, si el objetivo es el acceso a dietas saludables, se necesitan acciones adicionales tales como: a) el diseño de guías alimentarias adecuadas, considerando alimentos disponibles,

\footnotetext{
${ }^{24}$ Por ejemplo, está el caso de la Tarjeta Alimentar, en el marco del Plan Argentina contra el Hambre (PACH). El mismo, se articula sobre los hogares que reciben la Asignación Universal por Hijo, sin expandir la cobertura (e incurrir en costos asociados con un nuevo estudio de focalización), pero para los que la reciben significa una reducción de la brecha respecto de la línea de indigencia (o quizás hasta su eliminación). EI PACH enfatiza también el derecho a la buena alimentación, lo que es más amplio que el acceso al nivel básico de calorías y requeriría considerar los tres problemas de malnutrición (desnutrición, obesidad y sobrepeso y deficiencias de macro y micronutrientes). Esto requiere especificar con mayor detalle el alcance de esos problemas, los grupos afectados, y los objetivos que se esperan obtener bajo el PACH, indicando también si ellos abarcan a toda la población, o a un subconjunto de la misma (Salvia, Britos, y Díaz-Bonilla, eds, 2020).
} 
costos asociados y hábitos de la población objetivo; b) establecimiento de estrategias de educación alimentaria, empleando diversos medios de comunicación para llegar exitosamente a la mayor cantidad de personas vulnerables, con mensajes sencillos y concretos (por ejemplo, compartiendo recetas y usos de distintos alimentos) y c) empleo de etiquetado frontal fácilmente comprensible de alimentos, para identificar aquellos que deben consumirse con moderación debido al alto contenido calórico y bajo aporte nutritivo, acompañando con evaluación científica del impacto de este tipo de proyectos.

Como se mencionó antes, usualmente se necesitan también intervenciones con foco específico en mujeres embarazadas y familias con niños en temprana infancia (hasta 6 años) y programas de comedores escolares. Es por esto, que se recomienda que este tipo de programas necesitan: a) clara definición de objetivos y articulación de políticas relacionadas dentro de las instituciones gubernamentales a cargo, para evitar duplicación de esfuerzos y gastos innecesarios de recursos, al tiempo que se permite detallar una estrategia de evaluación clara; b) dado que se extienden dentro del programa esfuerzos hacia mujeres embarazadas y niños en primera infancia, incluir programas de promoción de la lactancia materna; c) para garantizar el éxito de las prestaciones alimentarias directas a la población objetivo, diseñar tanto la cobertura, así como calidad de comedores escolares (incluyendo los comunitarios, si hubiera), considerando flexibilidad por disponibilidad, costos y tradiciones.

Estos programas pueden articularse con mecanismos de compra gubernamentales que prioricen el apoyo para pequeños productores. Sin embargo, hay que tener en cuenta que al aumentar la cantidad de objetivos, también aumenta la complejidad de los esfuerzos, por lo que es necesario fortalecer y clarificar herramientas de seguimiento y mecanismos de evaluación y monitoreo.

\section{e) Programas especiales de transferencias para pobres rurales}

En Latinoamérica hay un debate sobre si lo que corresponde es la ampliación de los servicios y programas sociales universales sobre la base de un enfoque de derechos para todos, o si se necesitan programas focalizados. Obviamente, lo ideal es un sistema de programas y servicios universales de calidad, para la población urbana y la rural, y para todos los niveles económicos sin distinción. Pero, mientras se trabaja en la expansión y fortalecimiento de los servicios universales, se pueden ir mejorando en paralelo los enfoques focalizados en camino hacia esquemas universales de calidad basados en derechos.

Un segundo debate respecto de los programas de asistencia social, como es el caso de los esquemas de transferencias condicionadas, es si debería haber diferencias entre los enfoques urbanos y rurales. Algunos argumentan que en la práctica de muchos de los países de la región los programas de asistencia social en las zonas rurales han sido simplemente una extensión mecánica del sistema de protección social urbana (ver por ejemplo, FAO, 2016).

Esta discusión está llevando a considerar el desarrollo de modelos específicos de protección social que consideren las características específicas del campesinado, productores pequeños, 
y trabajadores informales en las zonas rurales (ver, por ejemplo, Natalia Winder 2018; Ana Nehring, Ryan y De la O Campos, 2019; FAO, 2016, 2017 y 2018).

Venezuela debería analizar la adecuación de los programas de transferencias condicionadas en las zonas rurales, incorporando los aspectos de asistencia social, pero también ampliando el foco hacia temas productivos y tecnológicos que puedan contribuir a mejorar la sostenibilidad económica y ambiental de las familias involucradas. Acá se sugiere el análisis y creación de un instrumento para el área rural que pueda combinar lo social, productivo, y ambiental, por ejemplo, con un porcentaje de ingresos relacionado con los niveles de pobreza; otro para cubrir el costo adicional de implementar tecnologías sostenibles de adaptación y mitigación; otro para servicios ambientales, forestales, de biodiversidad y de protección/restauración de ecosistemas; y que, en general, incluya otras formas de apoyo productivo, organizativo, y comercial para los productores pobres.

Este enfoque está en línea con Gilligan (2020), quien hace una revisión de la evidencia y literatura de una variedad de programas sociales y sus resultados alrededor del mundo. El autor nota que los programas de protección social mediante transferencias regulares tienen efectos en la disminución de la pobreza y contribuyen a la acumulación de activos en los hogares. Sin embargo, existe poca evidencia que estos activos contribuyan a mejoras sustanciales tanto agrícolas como de ingresos posteriores si no se combinan con programas de acceso a tecnología agrícola y entrenamiento que sirva para superar obstáculos en el acceso a insumos productivos, financiamiento e información.

Este tipo de programa más amplio, ayudaría en toda una serie de dimensiones para el desarrollo económico y social de los habitantes rurales con un enfoque de refuerzo de activos (humanos, financieros, tecnológicos, naturales, físicos, sociales, políticos) en manos de las poblaciones más pobres y vulnerables, reforzando la resiliencia de las comunidades rurales.

El nuevo enfoque debe considerar la heterogeneidad de las actividades productivas rurales (incluyendo forestación y pesca, además de las producciones agrícolas y pecuarias, junto con otras actividades no primarias rurales), sus características, potencialidades y vulnerabilidades específicas, y cómo se insertan en las estrategias de supervivencia de las personas y familias pobres y vulnerables (ver, por ejemplo, Natalia Winder, 2018 y FAO, 2018).

El diseño tiene que tomar en cuenta otros aspectos como la estacionalidad, la dispersión y/o lejanía geográfica, la operación de los mercados laborales (informalidad, inseguridad), aspectos relacionados con la participación de mujeres, grupos étnicos, jóvenes, y temas como violencia y migraciones.

Sistemas de transferencias de ingresos bien diseñados e implementados tienen una serie de resultados positivos (ver, por ejemplo, FAO, 2016):

- Reducen directamente la pobreza mediante la provisión de ingresos y de apoyo productivo a los hogares pobres y vulnerables.

- Mejoran la seguridad alimentaria 
- Eliminan los obstáculos de liquidez y crédito para que los campesino y pequeños productores puedan invertir en actividades agrícolas más productivas y rentables.

- Funcionan como seguro de riesgo contra diferentes eventualidades climáticas, de mercado, y relacionadas con la salud

- Eliminan barreras de tipo financiero y social para el acceso a los servicios sociales (educación, salud, nutrición y otros), lo que mejora el capital humano, su productividad y empleabilidad.

- Promueven el desarrollo económico local, ya que esos ingresos de liquidez tienen efectos multiplicadores "keynesianos" al aumentar la demanda local.

- Fomentan la resiliencia y sostenibilidad ambiental y el buen uso de los recursos naturales.

En este caso un programa bien diseñado e implementado debería superar las visiones asistencialistas y clientelistas, que generan dependencia, y pasaría a ser un elemento clave de un programa de desarrollo con transformación y revitalización de las economías rurales, centrado en fortalecer las capacidades y activos de sus habitantes, especialmente los más pobres y vulnerables.

\section{f) Costos}

En el "Pathways report" (2019) de este proyecto se presentaron algunas estimaciones de costos de programas de protección social en 2018 (Cuadro 4).

Cuadro 4: Estimado de Costos para Diferentes Opciones de Corto Plazo de Ayuda Alimentaria y Redes de Protección Social

Millones de USD/año

1.CLAPs a niveles erráticos

$320-420$

2.Cobertura completa de CLAPs, bajo las condiciones de 2017

$770-930$

3.Cobertura completa de CLAPs, bajo las condiciones de 2018

$1000-1200$

4.Programa sustancial de transferencias condicionadas a los niveles de po-

$2500-2700$ breza de 2018

Fuente: "Pathways report" (2019)

Las condiciones de pobreza en Venezuela se han deteriorado aún más en 2019, y la pandemia actual ha profundizado los niveles de pobreza e inseguridad alimentaria. De allí que, como se 
mencionó anteriormente la UCAB ha estimado que un programa de transferencias que permitiera cerrar la brecha de pobreza extrema tendría que otorgar algo más del equivalente de 2 dólares al día a unos 6,5 millones de hogares. Este programa, bajo el supuesto de una focalización perfecta, requeriría un presupuesto de cerca de 5,000 millones de dólares anuales.

Además, desde un punto de vista estrictamente alimentario, se necesitaría considerar mínimamente el costo de los comedores escolares y de los programas nutricionales materno-infantiles.

Considerando la enorme incertidumbre acerca de la evolución de la pandemia y de las condiciones económica, sociales y políticas en Venezuela, no es mucho más lo que se puede avanzar en la actualidad en la estimación de los costos para un programa integral de superación de la pobreza y la inseguridad alimentaria.

\section{g) Organización y gobernanza de los programas}

Tal como se mencionó anteriormente, el diseño de programas adecuados debe establecer claramente objetivos, e instrumentos, y luego, obviamente, un tema central es la capacidad organizativa y operacional para la implementación y monitoreo. Además, debe incluir clara definición y análisis de los incentivos, presupuestos, e inversiones necesarias para la coordinación intersectorial y niveles federal/provincial, con una clara esquematización de la coordinación a nivel territorial.

El tema de cómo "coordinar" o "articular" la variedad de políticas sociales se repite en todos los países. Hay varios enfoques para ello. Uno es preparar "planes sociales" que procuran consolidar la oferta de programas focalizados a cargo del Estado Nacional; otro es crear una instancia gubernamental para ejecutar esos programas (como los Ministerios o Secretarías de Desarrollo Social0; y un tercero es organizar el Gabinete Social, o un Consejo Nacional de Coordinación de Políticas Sociales (en el 2002). Sin embargo, las diferentes experiencias no parecen haber resuelto el tema de la coordinación o articulación de programas sociales.

Parte de los problemas organizativos y de gobernanza que enfrentan los programas sociales se deben al uso de planes generales (sin objetivos cuantitativos e instrumentos definidos); a que los enfoques organizativos simplemente cambian o reasignan funciones en organigramas; y a que los mecanismos de coordinación (Gabinetes o Consejos) carecen de una agenda clara y mecanismos formales para operacionalizar las decisiones. Lo que se requiere son mecanismos de programación y coordinación orientados a la acción y resultados, articulados alrededor del presupuesto.

Los problemas de funcionamiento no se resuelven necesariamente con cambios organizativos y de funciones, sino que requieren fundamentalmente una implementación disciplinadamente del ciclo de Programación, Ejecución y Control (PEC). 


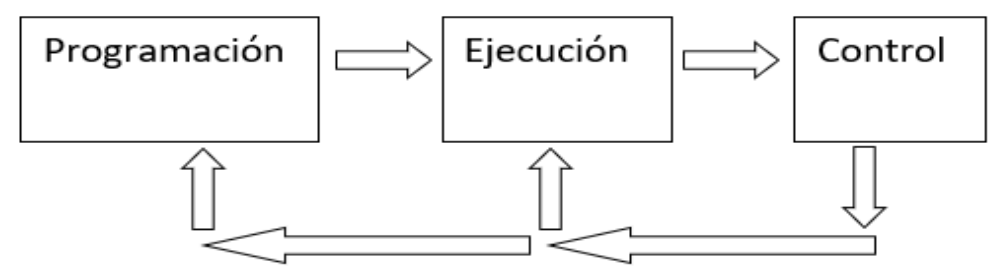

Este ciclo tiene como componentes un mecanismo obligatorio de programación y coordinación (al menos anual), orientado a la acción y resultados, y de control de ejecución (al menos semestral) y con un sistema de monitoreo usando preferentemente sistemas digitales con las familias participantes. En el mejor de los casos, no debería ser necesario la creación de nuevas instituciones o burocracia que se sumen a la complejidad actual, sino que se basan en el uso operacional y programático de recursos e instituciones existentes, articulados alrededor del ciclo presupuestario, que es deseable que sea plurianual.

El esquema requiere también la confección de padrones únicos de personas atendidas por los diferentes programas, junto con mecanismos de monitoreo desde las propias familias y personas participantes usando tecnologías digitales.

\section{h) Estadísticas, sistemas de información, y monitoreo y evaluación}

Para el adecuado seguimiento, evaluación y monitoreo de un programa, es necesario contar con sistemas de información y estadísticas adecuados y preestablecidos antes de la intervención, incluyendo, su adecuado geo-referenciamiento a nivel territorial.

Esto significa también contar con un registro de individuos o familias participantes para poder cruzar los beneficios obtenidos junto con los resultados de interés observados (cambios en ingresos, consumo, dietas, indicadores de salud y otras variables relevantes). Algunos problemas a considerar son cómo se garantiza la privacidad de la información, y que esos registros no serán usados con fines políticos clientelísticos.

Esta información debería integrar los datos de los Ministerios de Salud y de Educación sobre mediciones antropométricas y el desarrollo de controles de salud, con especial atención a la heterogeneidad de la cobertura territorial. Esa información debería traducirse en diagnósticos y visiones compartidas, que informen las actividades de los diferentes ministerios y agencias. Además, la información debería estar disponible en un sistema que permita el cruzamiento con otras fuentes de información (encuestas de calidad de vida, o de factores de riesgo) para caracterizar mejor la situación general.

Se deben aprovechar las ventajas de la digitalización para monitorear el otorgamiento de los servicios públicos que se supone que el gobierno está llevando adelante, mediante la informa- 
ción proporcionada por la población beneficiaria. Un ejemplo es el trabajo del IFPRI en el diseño del monitoreo de una serie de intervenciones de salud en Guatemala (Hernández, M., Miguel Robles, Francisco Ceballos, Mariana García Martínez, y Braulio Britos. 2016).

También se pueden utilizar sensores y tecnologías de información para asegurar inocuidad, calidad y trazabilidad de los alimentos; para manejar pérdidas y desperdicios; y para dar mayor transparencia y eficiencia a las cadenas de valor. Dado el impacto de la actual pandemia, y de otras zoonosis que han amenazado, o pueden afectar en el futuro la operación de las cadenas alimentarias, estos instrumentos digitales para trazabilidad y control de calidad adquieren aún mayor relevancia.

La digitalización puede servir, en general, para recoger datos de la población en diferentes formatos y para distintos temas. Por ejemplo, el CIFOR (uno de los centros del CGIAR localizado en Kenia) utiliza un mecanismo de información de la población ("crowdsourcing") con fotos sobre agua de ríos en zonas donde no existen estaciones medidoras. En el IFPRI se está experimentando con un sistema para recolectar información sobre dietas con fotos de los platos servidos e información inteligente para interpretar productos, porciones y traducir esto en nutrientes. Se espera que este sistema pueda dar resultados mucho más precisos que las encuestas tradicionales basados en la memoria de los encuestados.

Solamente con información adecuada se podrán diseñar, ejecutar, monitorear y evaluar programas que permitan eliminar los problemas de hambre y malnutrición en los países. 


\section{E. COMENTARIOS FINALES}

Este documento trata de ser un insumo en el diseño de programas de protección social en Venezuela bajo un sistema de gobernanza democrática. Dadas las muchas incertidumbres acerca de la evolución de la pandemia y de las condiciones económica, sociales y políticas en ese país, las ideas presentadas acá son provisionales.

Se procuró presentar las condiciones actuales en este sufrido país usando especialmente la información de la UCAB. Luego se revisaron una variedad de programas de protección social en ALC, enfatizando tres grupos: los programas de transferencias condicionadas; los comedores escolares, y una variedad de programas alimentarios.

La siguiente sección planteó un esquema para pensar el diseño e implementación, basado en responder una serie de preguntas relacionadas con a) la definición de grupos a atender y objetivos; b) el diseño de programas e instrumentos (lo que supone una teoría del cambio, respecto qué significa "resolver el problema" y cómo se lo haría); c) la organización y gobernanza, enfatizando no solamente los aspectos organizativos y de organización, sino la necesidad de establecer mecanismos de programación y coordinación orientados a la acción y resultados, articulados alrededor del presupuesto; d) costos; y e) sistemas de seguimiento y evaluación, lo que requiere un registro único de personas y familias atendidas, y mecanismos directos de consulta con los mismos acerca de cómo se están desarrollando los servicios de los programas sociales.

Es de esperar que una pronta restauración de la gobernanza democrática y de la convivencia social en Venezuela permita avanzar finalmente en el diseño e implementación de un programa integral de superación de la pobreza y la inseguridad alimentaria. 


\section{ANEXO 1. PROGRAMAS DE COMPLEMENTACION ALIMENTARIA ESCOLAR EN PAISES SELECCIONADOS DE AMERICA LATINA.}

\begin{tabular}{|c|c|c|c|c|c|}
\hline País & Programa & Objetivos & Alimentos entregados & Cobertura & Institucion \\
\hline Bolivia $^{25}$ & $\begin{array}{l}\text { Ley N N } 622 \text { de Alimenta- } \\
\text { ción Escolar en el } \\
\text { Marco de la Soberanía } \\
\text { Alimentaria y la Econo- } \\
\text { mía Plural }\end{array}$ & $\begin{array}{l}\text { 1.Garantizar progresivamente la } \\
\text { Alimentación Complementaria Es- } \\
\text { colar en las unidades educativas } \\
\text { del Sistema Educativo Plurinacio- } \\
\text { nal, con alimentos provenientes } \\
\text { de la producción local en el marco } \\
\text { del desarrollo integral para el Vivir } \\
\text { Bien } \\
\text { 2.Contribuir al rendimiento esco- } \\
\text { lar y promover la permanencia de } \\
\text { las y los estudiantes de las unida- } \\
\text { des educativas del Sistema Edu- } \\
\text { cativo Plurinacional, a través de la } \\
\text { alimentación sana, oportuna y } \\
\text { culturalmente apropiada. } \\
\text { 3.Fomentar la compra de produc- } \\
\text { tos destinados a la Alimentación } \\
\text { Complementaria Escolar, incenti- } \\
\text { vando y priorizando el consumo y } \\
\text { la producción local de alimentos. }\end{array}$ & $\begin{array}{l}\text { La producción y provisión de } \\
\text { alimentos para la Alimenta- } \\
\text { ción Complementaria Escolar } \\
\text { de las/los estudiantes de las } \\
\text { unidades educativas del Sis- } \\
\text { tema Educativo Plurinacional, } \\
\text { se sustenta en la complemen- } \\
\text { tariedad de acciones de los } \\
\text { diferentes niveles de go- } \\
\text { bierno, los proveedores y/o } \\
\text { productores locales y nacio- } \\
\text { nales de alimentos. } \\
\text { Se proveen alimentos en } \\
\text { forma permanente: Las enti- } \\
\text { dades territoriales autónomas } \\
\text { responsables de proveer Ali- } \\
\text { mentación Escolar, asistirán } \\
\text { en forma permanente durante } \\
\text { toda la gestión educativa, con } \\
\text { alimentos sanos, inocuos, de } \\
\text { calidad, nutritivos y cultural-- } \\
\text { mente apropiados, provenien- } \\
\text { tes de la producción local y } \\
\text { nacional. }\end{array}$ & Nivel Nacional & $\begin{array}{l}\text { Ministerio de Desa- } \\
\text { rrollo Productivo y } \\
\text { Economía Plural } \\
\text { Ministerio de Desa- } \\
\text { rrollo Rural y Tie- } \\
\text { rras }\end{array}$ \\
\hline Brasil & $\begin{array}{l}\text { El Programa Nacional } \\
\text { de Alimentos Escolares } \\
\text { (PNAE) } \\
\text { Con la Ley N } \circ 11.947 \text {, } \\
\text { del } 16 \text { de Junio de } 2009\end{array}$ & $\begin{array}{l}\text { Contribuir al crecimiento y desa- } \\
\text { rrollo bio-psicosocial, el aprendi- } \\
\text { zaje, rendimiento escolar y a la } \\
\text { formación de hábitos alimentarios } \\
\text { saludables de los estudiantes, a } \\
\text { través de acciones de educación }\end{array}$ & $\begin{array}{l}\text { Educación Alimentaria } \\
\text { y Nutricional recibe alimentos } \\
\text { de la Agricultura familiar (AF), } \\
\text { productos obtenidos de } \\
\text { proyectos y huertos escolares } \\
\text { Con la Ley } N^{\circ} 11.947 \text {, el } 30 \% \\
\text { del monto transferido por el }\end{array}$ & $\begin{array}{l}\text { Nivel Nacional: } 5,564 \text { Munici- } \\
\text { palidades; } \\
\text { Alumnos atendidos por el } \\
\text { PNAE } 45 \text { millones al día/ } 200 \\
\text { días al año } \\
\text { Escuelas } 190.000\end{array}$ & $\begin{array}{l}\text { El Gobierno Fede- } \\
\text { ral le transfiere } \\
\text { montos financieros } \\
\text { a los estados, mu- } \\
\text { nicipios y escuelas } \\
\text { federales }\end{array}$ \\
\hline
\end{tabular}

25 Plataforma CELAC. Ley № 622 de alimentación escolar en el marco de la soberanía alimentaria y la economía plural. Bolivia. https://plataformacelac.org/ley/90 
alimentaria y nutricional y el sumi- Programa Nacional de Ali-

nistro de alimentos para cubrir

sus necesidades nutricionales du- debe invertirse en la compra

rante el año escolar. ${ }^{26}$

- debe invertirse en la compra

directa de productos de la

agricultura familiar, una me-

dida que estimula el desarro-

llo económico y sostenible de

las comunidades. ${ }^{27}$

Chile $^{30}$
$\begin{aligned} & \text { Programa de Alimenta- } \\ & \text { ción Escolar }\end{aligned}$
Ley $N^{\circ} 15.720 / 1964$

Mejorar la asistencia a clases y retener a los estudiantes en el sistema educacional, a través de la entrega de un servicio de alimentación escolar saludable, variado y nutritivo, que les permita un desarrollo físico y mental que favorezca y estimule la concentración y aprendizaje necesarios para su éxito académico. des nutricionales del día de
Se entrega una ración diaria de alimentación por estudiante, complementaria y dif renciada, compuesta por: desayuno, almuerzo y/u once además en hogares se entrega desayuno, almuerzo once y cena. Cubre alrededo de un tercio de las necesidalos escolares de enseñanza básica y media y entre un 45 y un $50 \%$ de los requerimientos de los preescolares y en el caso de los hogares el $100 \%$ del requerimiento diario de los alumnos y alumnas beneficiarias.
Este programa cubre 200

días escolares de febrero a

noviembre. En el 2012, al-

canzo a más de 250000 institutos educativos. ${ }^{28}$ En 2014 PNAE benefició a 42.2 millo-

nes de estudiantes y además los recursos utilizados para la adquisición de alimentos de los pequeños agricultores alcanzaron más de (Reales) $\mathrm{R} \$ 711$ millones. ${ }^{29}$

Cobertura Nacional: Alumnos Junta Nacional de de familias que pertenecen al Auxilio Escolar y $60 \%$ más vulnerable o con Becas mayor desventaja socioeco-

nómica según registro social de hogares, que asisten a establecimientos educacio-

nales municipales y particulares subvencionados del país (adscritos al PAE), en los niveles de educación prebásica, básica, media y adultos.

\footnotetext{
${ }^{26}$ Najla Veloso. Programa Nacional de Alimentación Escolar de Brasil: Una Política Estratégica de Educación y de seguridad alimentaria y Nutricional. FAO. http://www.fao.org/ag/humannutrition/30438-0aab101eed4d8130a9d0ad8b5f633df1.pdf

${ }^{27}$ PNAE Programa Nacional da Alimentação Escolar. Brasil https://www.fnde.gov.br/index.php/programas/pnae

${ }^{28}$ Alimentación Escolar y las Posibilidades de Compra Directa de la Agricultura Familiar. FAO. 2013. Estudio de Caso en Ocho Países, Cooperación Brasil-FAO, Fortalecimiento de Programas de Alimentación Escolar en el Marco de la, Iniciativa América Latina y Caribe Sin Hambre 2025, Proyecto GCP/RLA/180/BRA, http://www.rlc.fao.org/es/programabrasilfao ${ }^{29}$ Schools as a System to Improve Nutrition. 2017. https://www.unscn.org/uploads/web/news/document/School-Paper-EN-WEB.pdf

30 Plataforma CELAC. Programa de Alimentación Escolar. Chile. https://plataformacelac.org/programa/296
} 

ción Escolar

Documento Consejo Nacional de Política Económica y Social 113, 2008: Política Nacional de Seguridad Alimentaria y Nutricional.

Costa Rica ${ }^{34}$ Programa de alimentación y nutrición del es colar y del adolescente $^{35}$

Constitución Política (1949). Artículo 21 título $4^{\circ}$ Derechos y Garan-

tías Individuales, ar-

tículo 50 del título quinto sobre "Derechos y Garantías Sociales"

-Decreto N 30256 Etiquetado Nutricional de los Alimentos

Ecuador $^{37}$ adolescentes en edad escoy promover hábitos alimentarios acuerdo con la nueva meto-
Programa de Alimentación Escolar
Colegios en áreas rurales, que atiendan comunidades étnicas, víctimas del conflicto

Contribuir al acceso con perma- Ofrecer un complemento alinencia escolar de las niñas, niños mentario a las niñas, niños y y adolescentes en edad escolar, (ar, registrados en la matrícula fomentando estilos de vida salu- oficial, que aporte los requeridables y mejorando su capacidad mientos de energía, macronude aprendizaje, a través del suministro de un complemento alimentario.

Grupo meta:

trientes (carbohidratos, prote

nas y grasas) y micronutrientes (hierro, y calcio), en los porcentajes que se definan para cada modalidad durante la jornada escolar.

Ofrecer una alimentación comple- El menú debe ser adecuado mentaria a la población estudiantil para la edad, suficiente para saludables, hábitos de higiene y comportamientos adecuados en torno a la alimentación diaria.

la energía necesaria, y culturalmente apropiado. El go-

bierno tiene una descripción completa del menú de desayunos y almuerzos ${ }^{36}$ Se incluyen leguminosas, frutas, verduras, pastas, sopas, vegetales con carne, carnes semimagras, verduras, picadillos, arroces compuestos

armado, o con alta concen-

tración de población con

puntajes de SISBEN ${ }^{32}$ 48,49 Ministerio de Edupara 14 ciudades y 45,34 para resto urbano, de dología del SISBEN III.

Nacional; Actualmente el Programa de Nutrición y Alimentación del Escolar y el Adolescente (PANEA) del Ministerio de Educación Pública cubre el $96.1 \%$ del total de centros educativos, asegurando alimentación al $88.3 \%$ de la población estudiantil costarricense inscrita en el sistema de educación pública.

Institucion

Consejo Nacional de Política Económica y Social (CONPES)

cación $^{33}$

Ministerio de Educación Pública

Contribuir al mejoramiento de la calidad y eficiencia de la educación básica mediante la entrega
Desayuno: Compuesto de una Niños, niñas entre 3 y 5 años Ministerio de Educolada fortificada de sabores y galleta rellena o tradicional: niñas y adolescentes de 5 a de educación inicial; y niños, cación e Instituto

\footnotetext{
31 Plataforma CELAC. Programa de Alimentación Escolar. Colombia. https://plataformacelac.org/programa/366
}

${ }^{32}$ EI SISBEN: EI Sisbén es la principal herramienta con que cuenta el Gobierno de Colombia para la focalización del gasto social que garantice que los programas sociales lleguen a las personas que viven la pobreza en sus diferentes formas. http://www.sdp.gov.co/gestion-estudios-estrategicos/sisben/metodologia-4

${ }^{33}$ Mineducación, Ministerio de Educación Nacional - República de Colombia PAE http://www.mineducacion.gov.co/1621/w3-article-327088.html

34 Plataforma CELAC. Programa de Alimentación y nutrición del escolar y del adolescente. Costa Rica. https://plataformacelac.org/programa/301

${ }^{35}$ Programa de Alimentación y Nutrición del Escolar y del Adolescente (PANEA). Gobierno de Costa Rica. http://www.mep.go.cr/programas-y-proyectos/programa-de-alimentacion-ynutricion

${ }^{36}$ Manual de Menú para Comedores Estudiantiles de primaria https://www.mep.go.cr/sites/default/files/page/adjuntos/manual-primaria.pdf

37 Plataforma CELAC. Programa de Alimentación Escolar. Ecuador. https://plataformacelac.org/programa/41 
Ley Orgánica del Régi- de un complemento alimenticio,

men de la Soberanía

Alimentaria

Decreto № 696 barra de cereal, y granola. en envase tetra brik de leche

Como parte de este Programa En el año escolar 2017-2018, Ministerio de Eduse entrega frijol, arroz, azúcar, se alcanzaron a 1,168,837

Guatemala $^{39}$ Programa de Desayunos Escolares

Entregar una refacción escolar a todos los niños y niñas del país en las modalidades de preescolar y primaria.
Refrigerio consiste en $200 \mathrm{ml}$ de sabores y entera.

Almuerzo: El almuerzo escolar es entregado listo para el consumo en las Instituciones Educativas, su elaboración se efectúa en base a requerimientos nutricionales de los

escolares de acuerdo al grupo de edad, y su preparación es realizada con productos frescos de la zona, propiciando la compra local y directa a pequeños productores. aceite, bebida fortificada y le- estudiantes de 5,102 centros che en polvo, ésta última para educativos, 220 centros de aquellos centros escolares que aún no reciben leche líquida.

14 años de educación geneeducativas públicas de las

Entrega de desayunos escolares compuestos por un ato elaborado de Incaparina y

cinco menús elaborados con Protemás entre otros alimentos preparados por las madres de los alumnos.
Atención Inicial del Instituto Salvadoreño para el Desarrollo Integral de la Niñez y Adolescencia y 42 centros rurales de nutrición del Ministerio de Salud. zonas rurales y urbanas (con alimentación); y estudiantes de instituciones educativas gerio)

Zonas Rurales y Urbanas

\section{cación}

caciós

de Provisión de Ali-

mentos

24.840 escolares reciben el desayuno anualmente.

Ministerio de Educación

Todos los niños y niñas de país en las modalidades de preescolar y primaria.

\footnotetext{
38 Plataforma CELAC. Programa de Alimentación y salud Escolar. El Salvador. https://plataformacelac.org/programa/132
}

39 Plataforma CELAC. Programa de Desayunos Escolares. Guatemala. https://plataformacelac.org/programa/159 


\begin{tabular}{|c|c|c|c|c|c|}
\hline País & Programa & Objetivos & Alimentos entregados & Cobertura & Institucion \\
\hline Honduras $^{40}$ & $\begin{array}{l}\text { Programa Escuelas Sa- } \\
\text { ludables } \\
\text {-Decreto Ejecutivo No. } \\
\text { PCM-0001-2000 De- } \\
\text { creto N }{ }^{\circ} 54-2010, \text { - Ley } \\
\text { del vaso de Leche para } \\
\text { el fortalecimiento de la } \\
\text { Merienda Escolar - } \\
\text { Reglamento General de } \\
\text { la Ley Del Vaso de Le- } \\
\text { che para fortalecimiento } \\
\text { a la Merienda Escolar }\end{array}$ & $\begin{array}{l}\text { El Programa busca la reducción } \\
\text { de los índices de desnutrición, de- } \\
\text { serción y repitencia escolar; au- } \\
\text { mentando la asistencia y el rendi- } \\
\text { miento académico de los escola- } \\
\text { res en ambientes y entornos favo- } \\
\text { rables para la vida con la partici- } \\
\text { pación activa de los padres y ma- } \\
\text { dres de familia, comunidad e insti- } \\
\text { tuciones. }\end{array}$ & $\begin{array}{l}\text { Merienda escolar urbana y ru- } \\
\text { ral; Implementación de huer- } \\
\text { tos escolares. } \\
\text { Entrega de micronutrientes, } \\
\text { desparasitantes, vacunas y } \\
\text { realiza capacitaciones. Vita- } \\
\text { mina A: se proporciona una } \\
\text { (1) cápsula de } 200,000 \text { U.I. a } \\
\text { los mayores de seis años, dos } \\
\text { veces al año (marzo y sep- } \\
\text { tiembre). } \\
\text { Hierro: de preferencia amino- } \\
\text { quelado y complementado } \\
\text { con ácido fólico (este se ab- } \\
\text { sorbe en un } 90 \% \text { comparado } \\
\text { con } 60 \% \text { del sulfato ferroso, } \\
\text { siendo las molestias gástricas } \\
\text { mínimas), una tableta de } 30 \\
\text { mg o sulfato ferroso de } 300 \\
\text { mg semanalmente }\end{array}$ & $\begin{array}{l}\text { La población escolar de los } \\
\text { centros educativos rurales y } \\
\text { urbanos- marginales, de los } \\
\text { municipios con más alta vul- } \\
\text { nerabilidad del país. }\end{array}$ & $\begin{array}{l}\text { Secretaría de } \\
\text { Desarrollo e Inclu- } \\
\text { sión Social } \\
\text { Secretaría de Edu- } \\
\text { cación } \\
\text { Presidencia de la } \\
\text { República de Hon- } \\
\text { duras }\end{array}$ \\
\hline Jamaica $^{41}$ & $\begin{array}{l}\text { Jardín Escolar Nacio- } \\
\text { nal/National School } \\
\text { Garden } \\
\text { Constitución Política de } \\
\text { 1962 Derecho a la Ali- } \\
\text { mentación en Jamaica }\end{array}$ & $\begin{array}{l}\text { Equipar a todos los estableci- } \\
\text { mientos educacionales públicos } \\
\text { de jardines escolares, dirigidos a } \\
\text { proveer, a los jóvenes, de habili- } \\
\text { dades y conocimiento necesarios, } \\
\text { para desarrollar la agricultura y } \\
\text { promover el emprendimiento en el } \\
\text { campo. }\end{array}$ & $\begin{array}{l}\text { El programa otorga los mate- } \\
\text { riales para la construcción de } \\
\text { los jardines escolares. Tam- } \\
\text { bién construye y mantiene los } \\
\text { jardines escolares y genera } \\
\text { las instancias pedagógicas } \\
\text { para que los jóvenes interac- } \\
\text { túen e intervengan en los jar- } \\
\text { dines. }\end{array}$ & $\begin{array}{l}\text { Cobertura urbano-rural, jóve- } \\
\text { nes en etapa escolar prima- } \\
\text { ria, secundaria y terciaria. }\end{array}$ & $\begin{array}{l}\text { Autoridad de Desa- } \\
\text { rrollo Agricultural } \\
\text { Rural }\end{array}$ \\
\hline México $^{42}$ & $\begin{array}{l}\text { Programa de Desayu- } \\
\text { nos Escolares }\end{array}$ & $\begin{array}{l}\text { Contribuir a la seguridad alimen- } \\
\text { taria de la población escolar, su- } \\
\text { jeta de asistencia social, me- } \\
\text { diante la entrega de desayunos } \\
\text { calientes, desayunos fríos, dise- } \\
\text { ñados con base en los Criterios } \\
\text { de Calidad Nutricia, y acompaña- } \\
\text { dos de acciones de orientación }\end{array}$ & $\begin{array}{l}\text { El desayuno o comida escolar } \\
\text { caliente se compone de: } \\
\text { 1. Leche descremada y/o agua } \\
\text { natural. } \\
\text { 2. Un platillo fuerte que incluya } \\
\text { verduras, un cereal integral, } \\
\text { una leguminosa y/o un alimentc } \\
\text { de origen animal. }\end{array}$ & $\begin{array}{l}\text { Niñas, niños y adolescentes } \\
\text { en condiciones de riesgo y } \\
\text { vulnerabilidad, que asisten a } \\
\text { planteles oficiales del Sis- } \\
\text { tema Educativo Nacional, } \\
\text { ubicados en zonas indíge- } \\
\text { nas, rurales y urbano-margi- } \\
\text { nadas, preferentemente. El }\end{array}$ & $\begin{array}{l}\text { Sistema Nacional } \\
\text { para el Desarrollo } \\
\text { Integral de la Fami- } \\
\text { lia }\end{array}$ \\
\hline
\end{tabular}

40 Plataforma CELAC. Programa Escuelas Saludables. Honduras. https://plataformacelac.org/programa/211

41 Plataforma CELAC. Jardín Escolar Nacional. Jamaica. https://plataformacelac.org/programa/254

42 Plataforma CELAC. Programa de Desayunos Escolares. México. https://plataformacelac.org/programa/116 


\begin{tabular}{|c|c|c|c|c|c|}
\hline País & Programa & Objetivos & Alimentos entregados & Cobertura & Institucion \\
\hline & & $\begin{array}{l}\text { alimentaria, aseguramiento de la } \\
\text { calidad alimentaria y producción } \\
\text { de alimentos. }\end{array}$ & 3. Fruta. & $\begin{array}{l}\text { Programa distribuye } 6 \text { millo- } \\
\text { nes } 92 \text { mil } 103 \text { raciones ali- } \\
\text { mentarias diarias en } 80 \text { mil } \\
746 \text { escuelas de nivel prees- } \\
\text { colar, primaria y secundaria, } \\
\text { de las cuales, } 50 \% \text { se otor- } \\
\text { gan en su modalidad caliente } \\
\text { a través de las casi } 40 \text { mil } \\
\text { cocinas escolares instaladas } \\
\text { en los } 32 \text { estados del país. }{ }^{43}\end{array}$ & \\
\hline Nicaragua ${ }^{44}$ & $\begin{array}{l}\text { Programa Integral de } \\
\text { Nutrición Escolar }\end{array}$ & $\begin{array}{l}\text { Mejorar el nivel nutricional y el ac- } \\
\text { ceso a la educación, promoviendo } \\
\text { la asistencia y retención escolar, } \\
\text { de niños y niñas, con la participa- } \\
\text { ción de la comunidad y una estre- } \\
\text { cha coordinación interinstitucional } \\
\text { en municipios con muy alta y alta } \\
\text { inseguridad alimentaria y extrema } \\
\text { pobreza. }\end{array}$ & $\begin{array}{l}\text { El programa provee una Me- } \\
\text { rienda a estudiantes de nivel } \\
\text { preescolar y primario de todas } \\
\text { las escuelas públicas del país, } \\
\text { y un desayuno escolar a los } \\
\text { alumnos de municipios en si- } \\
\text { tuación nutricionalmente más } \\
\text { críticas. }\end{array}$ & $\begin{array}{l}\text { Alcance Nacional Niños -Ni- } \\
\text { ñas entre } 3 \text { y } 12 \text { años esco- } \\
\text { larizados (2012) } \\
\text { Cobertura } 1.020 .447 \text { niñas y } \\
\text { niños de preescolar y prima- } \\
\text { ria. }\end{array}$ & $\begin{array}{l}\text { Ministerio de Edu- } \\
\text { cación }\end{array}$ \\
\hline Panamá 45 & $\begin{array}{l}\text { Merienda Escolar } \\
\text { Educación Alimentaria } \\
\text { Nutricional }\end{array}$ & $\begin{array}{l}\text { El programa se enfoca en los ni- } \\
\text { ños y niñas que diariamente acu- } \\
\text { den a establecimientos escolares, } \\
\text { ofreciendo productos nutriciona- } \\
\text { les de alta calidad que además de } \\
\text { contribuir con su aporte de ener- } \\
\text { gía (de } 320 \text { a } 330 \text { kcal por modali- } \\
\text { dad) equivalente al de una me- } \\
\text { rienda ligera, cumplen también } \\
\text { con una serie de nutrientes (ma- } \\
\text { cro y micronutrientes) indispensa- } \\
\text { bles para el adecuado creci- } \\
\text { miento y desarrollo de los escola- } \\
\text { res. }\end{array}$ & $\begin{array}{l}\text { El programa entrega una me- } \\
\text { rienda escolar compuesta por } \\
\text { galletas nutricionalmente me- } \\
\text { joradas, bebida láctea y } \\
\text { crema nutritiva enriquecida, } \\
\text { conformada por un paquete } \\
\text { de } 34 \text { gramos de galletas, } 8 \\
\text { onzas de bebida láctea u } 8 \\
\text { onzas de crema nutritiva. }\end{array}$ & $\begin{array}{l}\text { Cobertura público urbano. El } \\
\text { Ministerio de Educación, ga- } \\
\text { rantiza la entrega de produc- } \\
\text { tos altamente nutritivos a } \\
\text { cerca de } 500.000 \text { niños y ni- } \\
\text { ñas que acuden diariamente } \\
\text { a los más de } 3.500 \text { centros } \\
\text { de educativos a nivel nacio- } \\
\text { nal. }\end{array}$ & $\begin{array}{l}\text { Ministerio de Edu- } \\
\text { cación }\end{array}$ \\
\hline Perú & & $\begin{array}{l}\text { Mejorar el estado nutricional de } \\
\text { los niños-niñas más pobres a tra- } \\
\text { vés de la entrega de leche para }\end{array}$ & $\begin{array}{l}\text { Ofrece una ración diaria de } \\
250 \text { mil de leche un alimento } \\
\text { equivalente. Las raciones se }\end{array}$ & $\begin{array}{l}\text { Cobertura nacional: Existen } \\
\text { unos } 3 \text { millones de beneficia- } \\
\text { rios que están asociados a }\end{array}$ & $\begin{array}{l}\text { Gobiernos Locales. } \\
\text { Las municipalida- }\end{array}$ \\
\hline
\end{tabular}

\footnotetext{
43 Gobierno de México. Desayunos escolares Calientes. https://www.gob.mx/difnacional/acciones-y-programas/desayunos-escolares-calientes

44 Plataforma CELAC. Programa Integral de Nutrición Escolar. Nicaragua. https://plataformacelac.org/programa/1 y https://www.mined.gob.ni/

45 Plataforma CELAC. Merienda Escolar. Panamá. https://plataformacelac.org/programa/330
} 


\begin{tabular}{|c|c|c|c|c|c|}
\hline \multirow[t]{2}{*}{ País } & Programa & Objetivos & Alimentos entregados & Cobertura & Institucion \\
\hline & $\begin{array}{l}\text { Vaso de Leche }{ }^{46} \\
\text { Programa social creado } \\
\text { mediante la Ley № } \\
24059 \text { y complemen- } \\
\text { tada con la Ley № } \\
27470,\end{array}$ & $\begin{array}{l}\text { los desayunos. Ofrece una ración } \\
\text { diaria de alimentos a la población } \\
\text { vulnerable, con el propósito de } \\
\text { ayudarla a superar la inseguridad } \\
\text { alimentaria } \\
\text { Los principales beneficiarios son } \\
\text { los niños de } 0 \text { a } 6 \text { años }(61,2 \%), \\
\text { seguido por los niños de } 7 \text { a } 13 \\
\text { años ( } 18,1 \%) \text {, adultos mayores y } \\
\text { pacientes con tuberculosis. }\end{array}$ & $\begin{array}{l}\text { entregan semanal o mensual- } \\
\text { mente a los } 1834 \text { municipios } \\
\text { del país, entre provinciales y } \\
\text { distritales. }\end{array}$ & $\begin{array}{l}\text { los más de } 66000 \text { Comités } \\
\text { de Vaso de Leche. El Depar- } \\
\text { tamento de Cajamarca } \\
\text { cuenta con el mayor número } \\
\text { de comités y beneficiarios } \\
(7,2 \text { y } 6,2 \%) \text {, seguido por } \\
\text { Piura }(6,7 \text { y } 5,4 \%) \text { y Puno } \\
(5,9 \text { y } 5,2 \%)^{47}\end{array}$ & $\begin{array}{l}\text { des son responsa- } \\
\text { bles de la ejecu- } \\
\text { ción del Programa, } \\
\text { en coordinación } \\
\text { con la Organiza- } \\
\text { ción del "Vaso de } \\
\text { Leche." }\end{array}$ \\
\hline Perú & $\begin{array}{l}\text { Proyecto Qali Warma } \\
\text { Ley General de Salud. } \\
\text { Art. } 10 \text { regula el dere- } \\
\text { cho a una alimentación } \\
\text { sana y suficiente }\end{array}$ & $\begin{array}{l}\text { Mejorar la alimentación de los ni- } \\
\text { ños desde los } 3 \text { años, matricula- } \\
\text { dos en instituciones educativas } \\
\text { públicas. }{ }^{48} \text { Garantizar una alimen- } \\
\text { tación diaria, variada, balan- } \\
\text { ceada, de calidad y adecuada a } \\
\text { los requerimientos nutricionales, a } \\
\text { través de un menú contextuali- } \\
\text { zado, en congruencia con los pa- } \\
\text { rámetros socioculturales y econó- } \\
\text { micos del entorno, así como la } \\
\text { disponibilidad de los productos e } \\
\text { insumos alimenticios característi- } \\
\text { cos de las regiones. }\end{array}$ & $\begin{array}{l}\text { Qali Warma considera las re- } \\
\text { comendaciones del Centro } \\
\text { Nacional de Alimentación y } \\
\text { Nutrición (CENAN) y con la } \\
\text { asistencia técnica del Pro- } \\
\text { grama Mundial de Alimentos } \\
\text { (PMA) ha establecido el } \\
\text { aporte de energía y nutrientes } \\
\text { que debe comprender el ser- } \\
\text { vicio alimentario } \\
\text { Los miembros de la comuni- } \\
\text { dad deciden los ingredientes } \\
\text { que se utilizarán en el menú } \\
\text { de las escuelas de determi- } \\
\text { nada zona y se encargan de } \\
\text { comprarlos. El sector privado } \\
\text { cubre otro vacío importante, } \\
\text { pues garantiza que la dieta de } \\
\text { los niños sea variada y cum- } \\
\text { pla con parámetros nutriciona- } \\
\text { les }{ }^{49} \text {. Estos son planeados se- }\end{array}$ & $\begin{array}{l}\text { Qali Warma atendió a más } \\
\text { de } 4 \text { millones de niños en } 64 \\
\text { mil instituciones públicas en } \\
\text { el } 2019,{ }^{50} \text { entre las que se in- } \\
\text { cluyen las de comunidades } \\
\text { indígenas de la región ama- } \\
\text { zónica peruana. } \\
\text { Productos ofrecidos: Pan con } \\
\text { granos andinos, pasas y le- } \\
\text { che, pan con aceituna, pan } \\
\text { con cebada, avena o ama- } \\
\text { ranto y mantequilla. } \\
\text { Pan con derivado lácteo: Pan } \\
\text { con Queso y leche. } \\
\text { Pan dulce: Chancay de } \\
\text { huevo, Pan de yema. Pan re- } \\
\text { gional: Pan de Plátano, Pan } \\
\text { integral. } \\
\text { Galletas: Galleta con ama- } \\
\text { ranto, galleta con quinua, ga- }\end{array}$ & $\begin{array}{l}\text { Ministerio de Desa- } \\
\text { rrollo e Inclusión } \\
\text { Social } \\
\text { (MIDIS) }\end{array}$ \\
\hline
\end{tabular}

${ }^{46}$ Diez-Canseco F, Saavedra-García L. Programas sociales y reducción de la obesidad en el Perú: reflexiones desde la investigación. Rev. Perú; Med Exp Salud Publica. 2017; 34(1):105-12. Doi: 10.17843/rpmesp.2017.341.2772

47 Ibid. Diez-Canseco, Saavedra-García L.

${ }^{48}$ Ibid, Diez-Canseco F, Saavedra-García L.

49 Andy Chi Tembon, Linda Brooke Schultz, Erick Fernandez . Alimentación escolar: Una herramienta para la inclusión social. Octubre 2015. The World Bank. https://blogs.worldbank.org/es/education/alimentaci-n-escolar-una-herramienta-para-la-inclusi-n-social

50 Info Qali Warma. https://www.qaliwarma.gob.pe/ y http://qaliwarma.gob.pe/InfoQaliwarma/\#/indicadores/prestacion-alimentaria ; CELAC https://plataformacelac.org/programa/185 


\begin{tabular}{|c|c|c|c|c|c|}
\hline País & Programa & Objetivos & Alimentos entregados & Cobertura & Institucion \\
\hline & & & $\begin{array}{l}\text { gún región (mayormente ce- } \\
\text { reales y productos de origen } \\
\text { animal). Los desayunos cu- } \\
\text { bren el } 20-25 \% \text { de los reque- } \\
\text { rimientos energéticos diarios; } \\
\text { los almuerzos aportan } 35 \% \text { - } \\
40 \% \text { de requerimientos ener- } \\
\text { géticos diarios }\end{array}$ & $\begin{array}{l}\text { lleta con cereales, galleta in- } \\
\text { tegral, galleta con maca, en- } \\
\text { tre otros. } \\
\text { Queque con granos andinos. } \\
\text { Snack Saludable: Maní con o } \\
\text { sin pasas. }\end{array}$ & \\
\hline $\begin{array}{l}\text { República Do- } \\
\text { minicana }^{51}\end{array}$ & $\begin{array}{l}\text { Programa de Alimenta- } \\
\text { ción Escolar }\end{array}$ & $\begin{array}{l}\text { Garantizar una alimentación dia- } \\
\text { ria, variada, balanceada, de cali- } \\
\text { dad y adecuada a los requeri- } \\
\text { mientos nutricionales, a través de } \\
\text { un menú contextualizado, en con- } \\
\text { gruencia con los parámetros so- } \\
\text { cioculturales y económicos del } \\
\text { entorno, así como la disponibili- } \\
\text { dad de los productos e insumos } \\
\text { alimenticios característicos de las } \\
\text { regiones. Además, promover una } \\
\text { acción pedagógica o cultural que } \\
\text { permita una formación de hábitos } \\
\text { alimentarios en la población esco- } \\
\text { lar atendida por el sistema educa- } \\
\text { tivo. }\end{array}$ & $\begin{array}{l}\text { El Programa ofrece: } 1 \text { - desa- } \\
\text { yunos cuya modalidad de- } \\
\text { pende de la ubicación geográ- } \\
\text { fica de los centros educativos; } \\
2-\text { almuerzos listos (contrata- } \\
\text { ción de empresas suplidoras), } \\
\text { o cocinado en el propio cen- } \\
\text { tro. 3- Merienda de jugo o pre- } \\
\text { parado lácteo. En esta moda- } \\
\text { lidad de implementa un menú } \\
\text { que se corresponde con cua- } \\
\text { tro semanas cíclicas, que per- } \\
\text { miten la elaboración de ali- } \\
\text { mentos variados, conforme } \\
\text { los requerimientos nutriciona- } \\
\text { les de los niños desde el Nivel } \\
\text { Inicial hasta el Nivel Medio. } \\
\text { Los centros reciben semanal- } \\
\text { mente este tipo de alimentos, } \\
\text { zanahorias, tomates y baca- } \\
\text { lao. }\end{array}$ & $\begin{array}{l}\text { Cobertura Nacional rural y } \\
\text { urbana; Actualmente cubre } \\
\text { cerca de } 1.4 \text { millones de es- } \\
\text { tudiantes en unos } 1.600 \text { cen- } \\
\text { tros educativos. } \\
\text { Existen } 3 \text { modalidades: } \\
\text {-PAE de Jornada Escolar Ex- } \\
\text { tendida } \\
\text {-PAE Fronterizo se imple- } \\
\text { menta en las comunidades } \\
\text { del suroeste y el noroeste, } \\
3.2 \% \text { de los establecimientos } \\
\text { reciben: habichuelas, guan- } \\
\text { dules, sardinas y salchichas. } \\
\text {-PAE REAL Ración Escolar } \\
\text { con alimentos locales: pláta- } \\
\text { nos verdes o maduros, sala- } \\
\text { mis, huevos, harina de maíz, } \\
\text { pan, queso, arroz, preparado } \\
\text { lácteo, zanahoria, tomate, } \\
\text { bacalao. } \\
\text {-PAE Urbano: leche blanca y } \\
\text { saborizada, jugos, néctares y } \\
\text { una ración sólida de pan y } \\
\text { galleta nutritiva. Esta modali- } \\
\text { dad cubre alrededor del } 92 \% \\
\text { de los centros educativos pú- } \\
\text { blicos existentes. }\end{array}$ & $\begin{array}{l}\text { Instituto Nacional } \\
\text { de Bienestar Estu- } \\
\text { diantil } \\
\text { Ministerio de Edu- } \\
\text { cación }\end{array}$ \\
\hline
\end{tabular}

51 Plataforma CELAC. Programa de Alimentación Escolar. República Dominicana. https://plataformacelac.org/programa/244 


\begin{tabular}{|c|c|c|c|c|c|}
\hline País & Programa & Objetivos & Alimentos entregados & Cobertura & Institucion \\
\hline Uruguay $^{52}$ & $\begin{array}{l}\text { Programa de Alimenta- } \\
\text { ción Escolar }\end{array}$ & $\begin{array}{l}\text { Complementar la alimentación } \\
\text { brindada en el hogar, favore- } \\
\text { ciendo la capacidad de aprendi- } \\
\text { zaje, mejorando el nivel de aten- } \\
\text { ción en el aula y el rendimiento } \\
\text { escolar de los niños y niñas que } \\
\text { asisten a los comedores de las } \\
\text { escuelas públicas del país. }\end{array}$ & $\begin{array}{l}\text { Distribución de menús al } \\
\text { desayuno, almuerzo y me- } \\
\text { rienda, y distribución de leche } \\
\text { fortificada. Además, vigilancia } \\
\text { del estado nutricional de los } \\
\text { niños en las escuelas públicas } \\
\text { de todo el país, le hace con- } \\
\text { trol de calidad e higiene de los } \\
\text { servicios en los comedores } \\
\text { escolares y lleva a cabo capa- } \\
\text { citación sobre Control de Cali- } \\
\text { dad e Higiene de los Alimen- } \\
\text { tos. }\end{array}$ & $\begin{array}{l}\text { Alcance nacional, cobertura } \\
\text { nacional rural y urbana, el } \\
\text { PAE brinda diariamente ali- } \\
\text { mentación a } 248.590 \text { escola- } \\
\text { res de escuelas públicas de } \\
\text { todo el país. } \\
67 \% \text { de niños matriculados } \\
\text { en escuelas públicas. El } 90 \% \\
\text { de las escuelas reciben al- } \\
\text { guna prestación alimentaria. } \\
\text { Asistencia alimentaria por } \\
\text { categoría de servicio: } \\
71 \% \text { - Almuerzo; } 16 \% \text { - } \\
\text { Desayuno o merienda. } \\
7 \% \text { - Desayuno, almuerzo y } \\
\text { merienda. } \\
5 \% \text { - Almuerzo y desayuno o } \\
\text { merienda. } \\
1 \% \text { - Desayuno, almuerzo, } \\
\text { merienda y cena. }\end{array}$ & $\begin{array}{l}\text { Consejo de Educa- } \\
\text { ción Inicial y Pri- } \\
\text { maria }\end{array}$ \\
\hline
\end{tabular}

Fuente: Biermayr-Jenzano, 2020

52 Plataforma CELAC. Programa de Alimentación Escolar. Uruguay. https://plataformacelac.org/pais/ury y http://www.cep.edu.uy/inicio-pae 


\section{BIBLIOGRAFIA}

Adato, Michelle and John Hoddinott, eds. Conditional Cash Transfers in Latin America. Baltimore: Johns Hopkins University Press, 2010. Pp. xviii+385.

Biermayr-Jenzano, Patricia. 2020. Medidas de protección social para la adopción de dietas sanas y accesibles en América Latina y el Caribe: Una revisión de la literatura. LAC Working Paper 10. Washington, DC: International Food Policy Research Institute (IFPRI). https://doi.org/10.2499/p15738coll2.134027

Cecchini, Simone. 2013. Social Transfers: Incentives and Disincentives to Labour Insertion and Income Generation, One Pager 236, International Policy Centre for Inclusive Growth.

Cecchini, Simone; Bernardo Atuesta, 2017. Programas de transferencias condicionadas en América Latina y el Caribe: tendencias de cobertura e inversión. CEPAL, Serie Políticas Sociales

Cecchini, S.; R. Martínez. 2011. Protección social inclusiva en América Latina: una mirada integral, un enfoque de derechos, Libros de la CEPAL, No. 111 (LC/G.2488-P CEPAL), Santiago de Chile, Comisión Económica para América Latina y el Caribe (CEPAL)

CEPAL. Base de datos de programas de protección social no contributiva en América Latina y el Caribe. https://dds.cepal.org/bpsnc/ptc

Collin Harguindeguy, Laura, Economía solidaria: local y diversa, El Colegio de Tlaxcala, A. C., Tlaxcala, México. 2014

Consolidacao, Programa Bolsa Família: uma década de inclusão e cidadania, T. Campello y M.Côrtes Neri (eds.), Brasilia, Instituto de Investigación Económica Aplicada (IPEA).

Departamento de Estado de los Estados Unidos, 2020. How Maduro has destroyed life inside Venezuela. 24 septiembre 2020. https://ge.usembassy.gov/how-maduro-has-destroyed-life-inside-venezuela/

Díaz-Bonilla, Eugenio. 2015. Macroeconomics, agriculture, and food security: A guide to policy analysis in developing countries. Washington, D.C.: International Food Policy Research Institute (IFPRI). http://dx.doi.org/10.2499/9780896298590

Diez-Canseco F, Saavedra-García L. 2017. Programas sociales y reducción de la obesidad en el Perú: reflexiones desde la investigación. 2017.Rev Peru Med Exp Salud Publica; 34(1):105-12. doi: 10.17843/rpmesp.2017.341.2772

FAO, 2013. "Las Cajas Urbanas: Una experiencia de financiación comunitaria liderada por mujeres". Cristina Rentería Garita, Karla Andino y Alberto Pantoja. Proyecto piloto para el fortalecimiento de la agricultura urbana y periurbana (APU) y de la seguridad alimentaria en el Distrito Central (Tegucigalpa, Comayagüela y alrededores), Honduras. FAO, Santiago, Chile, 2013, pp 4. http://www.fao.org/3/i3286s/i3286s.pdf

FAO. 2013. Alimentación Escolar y las Posibilidades de Compra Directa de la Agricultura Familiar Estudio de Caso en ocho Países, Cooperación Brasil-FAO, Fortalecimiento de Programas de Alimentación Escolar en el Marco de la, Iniciativa América Latina y Caribe Sin Hambre 2025, Proyecto GCP/RLA/180/BRA, http://www.rlc.fao.org/es/programabrasilfao

FAO, IFAD, UNICEF, WFP and WHO. 2019. The State of Food Security and Nutrition in the World. Safeguarding against economic slowdowns and downturns. Rome, FAO. http://www.fao.org/3/ca5162en/ca5162en.pdf

FAO, OPS, WFP y UNICEF. 2018. Panorama de la seguridad alimentaria y nutricional en América Latina y el Caribe 2018. Santiago. Número de páginas (133). Licencia: CC BY-NC-SA 3.0 IGO. FAO. PANORAMA.2018 pp. 11: http://www.fao.org/3/CA2127ES/CA2127ES.pdf

FAO-OPS. 2018. Políticas y programas alimentarios para prevenir el Sobrepeso y la Obesidad. Lecciones aprendidas. Número de documento: OPS/NMH/17-040; 18156ES/1/01.18 http://www.fao.org/3/i8156es//8156ES.pdf

FAO - WFP. 2019. Fortaleciendo los Programas de Alimentación Escolar: El trabajo conjunto de FAO y WFP en América Latina y el Caribe. Ciudad de Panamá. $44 \mathrm{pp}$.

Fernald LC, Gertler PJ, Neufeld LM. Role of cash in conditional cash transfer programs for child health, growth, and development: an analysis of Mexico's Oportunidades. Lancet. 2008; 371(9615):828-37. doi:10.1016/S0140-6736(08) 60382-7

Garcés, Sandra y Emma Kirwan .2009. Las canastas comunitarias en Ecuador: una apuesta por la salud, la economía y la solidaridad. FLACSO- Ecuador.

"Gentilini, Ugo; Almenfi, Mohamed; Orton, lan; Dale, Pamela. 2020. Social Protection and Jobs Responses to COVID-19 : A Real-Time Review of Country Measures. World Bank, Washington, DC. (C) World Bank. https://openknowledge.worldbank.org/handle/10986/33635 License: CC BY 3.0 IGO."

Gilligan, D. 2019. Safety Nets for Agriculture and Nutrition, CAB International 2019. Agriculture for Improved Nutrition: Seizing the Momentum. Eds S. Fan, S. Yosef and R. Pandya-Lorch. 
Gobierno de Uruguay. 2019. Sabores Andantes. Encuentros de Cocina Núcleo Interdisciplinario "Alimentación y Bienestar" Espacio Interdisciplinario | Udelar Comisión Sectorial de Investigación Científica | Udelar Instituto Nacional de Alimentación | Mides: https://www.gub.uy/ministerio-desarrollo-social/comunicacion/publicaciones/sabores-andantes-encuentroscocina

Hernández, M., Miguel Robles, Francisco Ceballos, Mariana García Martínez, y Braulio Britos. 2016. INFORME FINAL DE EVALUACIÓN DE IMPACTO DEL PLAN DEL PACTO HAMBRE CERO. International Food Policy Research Institute (IFPRI). Diciembre 2016. http://www.siinsan.gob.gt/siinsan/wp-content/uploads/Informe-Final-Evaluacion-ImpactoPPH0.pdf

Hidrobo, Melisa, John Hoddinott, Amber Peterman, Amy Margolies, Vanessa Moreira. 2014. Cash, food, or vouchers? Evidence from a randomized experiment in northern Ecuador, Journal of Development Economics, Volume 107, 2014, Pages 144-156, ISSN 0304-3878,https://doi.org/10.1016/j.jdeveco.2013.11.009.

Howe, Caitlin, 2008. Las Canastas Solidarias: Construyendo una comercialización directa con los productores. Primavera 2008. Pomona College. https://digitalcollections.sit.edu/cgi/viewcontent.cgi?article=1015\&context=isp collection

International Labour Organization - ILO. 2017. Cash transfer programmes, poverty reduction and women's economic empowerment: Experience from Mexico. Geneva.

Leroy, Jef L.; Olney, Deanna K.; and Ruel, Marie T. 2019. PROCOMIDA, a food-assisted maternal and child health and nutrition program, contributes to postpartum weight retention in Guatemala: A cluster-randomized controlled intervention trial. Journal of Nutrition 149(12): 2219-2227. https://doi.org/10.1093/jn/nxz175

Levy, S. y E. Rodríguez (2005), Sin herencia de pobreza. El programa Progresa-Oportunidades de México, Planeta - Banco Interamericano de Desarrollo (BID), Editorial Planeta, México DF.

Ministerio de Agricultura Familiar y Comunitaria. Nicaragua. 2017. Bono Productivo Alimentario: https://www.economiafamiliar.gob.ni/bono-productivo-alimentario/

Ministerio Secretaria General de Gobierno, Chile. 2008. Nueva Agenda Social. Programa Elige Vivir Sano;https://msgg.gob.cl/wp/2018/05/09/conoce-en-que-consiste-el-nuevo-sistema-elige-vivir-sano/

MSU, IFPRI, and team of experts in Venezuela. 2018. PATHWAYS REPORT. Outline of a Program for the Development of the Agrifood System in Venezuela. By. Washington DC

Nehring, Ryan; De la O Campos, Ana Paula 019 : Rural poverty reduction in the 21st century, Policy in Focus, No. 44, International Policy Centre for Inclusive Growth (IPC-IG), Brasilia

OPS/2005. 2005. Organización Panamericana de la Salud. Nutrition and an active life: from knowledge to action. Freire WB. Editor. Washington, D.C.: OPS; 2005.

OPS/OMS 2018. Indicadores Básicos. Situación de la Salud en las Américas. 2018.http://iris.paho.org/xmlui/bitstream/handle/123456789/49511/IndicadoresBasicos2018 spa.pdf?sequence=2\&isAllow $\underline{e d}=y \& u a=1$

Programa Mundial de la Alimentación. PMA. 2014. Manual sobre transferencias de efectivo y cupones. SEGUNDA EDICIÓN. Roma. Italia. https://docs.wfp.org/api/documents/WFP-0000015440/download/

PMA. 2017. Nutrir el Futuro Programas de Alimentación Escolar Sensibles a la Nutrición en América Latina y el Caribe Un Estu-dio de 16 Países.

PROSPERA.2016. Reglas de Operación de PROSPERA Programa de Inclusión Social, para el ejercicio fiscal 2017. http://www.gob.mx/cms/uploads/attachment/file/177672/Reglas de Operaci n 2017.pdf

Social Protection. Programa Productivo Alimentario, Nicaragua. Social Protection.org. https://www.socialprotection.org/discover/programmes/programa-productivo-alimentario-food-productive-programme

Stampini, Marco \& Leopoldo Tornarolli, 2012. The Growth of Conditional Cash Transfers in Latin America and the Caribbean: Did They Go Too Far? Inter-American Development Bank

UNSCN. 2017. Schools as a System to Improve Nutrition. https://www.unscn.org/uploads/web/news/document/School-PaperEN-WEB.pdf

UNOCHA, 2020. Venezuela: Informe de situación, agosto 2020. https://reliefweb.int/sites/reliefweb.int/files/resources/lnforme\%20de\%20situaci\%C3\%B3n\%20-\%20Venezuela\%20\%20-\%20Agosto\%202020\%20-\%2012\%20oct.\%202020.pdf

Vásquez Russi, Catalina María y Mónica, Uribe Gómez. 2019. Los estudios sobre los programas de transferencias monetarias condicionadas en América Latina: trayectorias, enfoques y perspectivas sobre la pobreza (June 18, 2019). OPERA No. 25, Julio-Diciembre, 2019. Accesible SSRN: https://ssrn.com/abstract=3406091

Word Bank. Andy Chi Tembon, Linda Brooke Schultz, Erick Fernandez. Alimentación escolar: Una herramienta para la inclusión social. Octubre 2015. https://blogs.worldbank.org/es/education/alimentaci-n-escolar-una-herramienta-para-la-inclusi$\underline{\text { n-social }}$ 
World Bank. 2018. The State of Social Safety Nets 2018. Washington, DC: World Bank. doi:10.1596/978-1-4648-1254-5

World Vision, 2020. EVALUACIÓN RÁPIDA MULTISECTORIAL PARA VENEZUELA. https://reliefweb.int/report/venezuelabolivarian-republic/evaluaci-n-r-pida-multisectorial-para-venezuela-septiembre-2020

World Vision, 2020. Venezuela, Crisis Response: Situation Report, Hope without Borders September 2020. https://reliefweb.int/sites/reliefweb.int/files/resources/Venezuela\%20Crisis\%20SitRep_September\%202020\%20\%282\%29.pdf

Yuriko Takahashi, 2017. "Varieties of Conditional Cash Transfers in Latin America," Working Papers 1619, Waseda University, Faculty of Political Science and Economics. Tokyo, Japan.

\section{SOBRE LOS AUTORES}

Eugenio Díaz-Bonilla es el Director del Programa de América Latina y el Caribe del IFPRI

Patricia Biermayr-Jenzano es consultora y profesora adjunta en la Universidad de Georgetown en Washington DC.

Florencia Paz es Analista de Investigación en la División de Mercados, Comercio e Instituciones y del Programa para Latinoamérica y el Caribe del IFPRI. 